\title{
Cochrane
}

Library

Cochrane Database of Systematic Reviews

\section{Antibiotic therapy for preventing infections in people with acute stroke (Review)}

Vermeij JD, Westendorp WF, Dippel DWJ, van de Beek D, Nederkoorn PJ

Vermeij JD, Westendorp WF, Dippel DWJ, van de Beek D, Nederkoorn PJ.

Antibiotic therapy for preventing infections in people with acute stroke.

Cochrane Database of Systematic Reviews 2018, Issue 1. Art. No.: CD008530.

DOI: 10.1002/14651858.CD008530.pub3.

www.cochranelibrary.com 
TABLE OF CONTENTS

HEADER

ABSTRACT

PLAIN LANGUAGE SUMMARY

SUMMARY OF FINDINGS

Figure 1.

BACKGROUND

OBJECTIVES

METHODS

RESULTS

Figure 2.

Figure 3.

Figure 4.

Figure 5.

Figure 6.

Figure 7.

DISCUSSION

AUTHORS' CONCLUSIONS

ACKNOWLEDGEMENTS

REFERENCES

CHARACTERISTICS OF STUDIES

DATA AND ANALYSES

Analysis 1.1. Comparison 1 Forest plot of comparison: primary outcomes, Outcome 1 Case fatality at the end of follow-up. ....

Analysis 1.2. Comparison 1 Forest plot of comparison: primary outcomes, Outcome 2 Death or dependency at the end of followup.

Analysis 2.1. Comparison 2 Forest plot of comparison: secondary outcomes, Outcome 1 Number of infections at the end of follow-up.

Analysis 2.2. Comparison 2 Forest plot of comparison: secondary outcomes, Outcome 2 Number of UTIs at the end of followup.

Analysis 2.3. Comparison 2 Forest plot of comparison: secondary outcomes, Outcome 3 Number of pneumonias at the end of follow-up.

Analysis 3.1. Comparison 3 Forest plot of comparison: sensitivity analyses, Outcome 1 Functional outcome: low risk of bias studies.

Analysis 3.2. Comparison 3 Forest plot of comparison: sensitivity analyses, Outcome 2 Number of infections: low risk of bias studies.

Analysis 3.3. Comparison 3 Forest plot of comparison: sensitivity analyses, Outcome 3 Case fatality: double-blind design. ...... Analysis 3.4. Comparison 3 Forest plot of comparison: sensitivity analyses, Outcome 4 Case fatality: open-label design. ......... Analysis 3.5. Comparison 3 Forest plot of comparison: sensitivity analyses, Outcome 5 Functional outcome: double-blind design.

Analysis 3.6. Comparison 3 Forest plot of comparison: sensitivity analyses, Outcome 6 Functional outcome: open-label design.

APPENDICES

WHAT'S NEW

CONTRIBUTIONS OF AUTHORS

DECLARATIONS OF INTEREST

SOURCES OF SUPPORT

INDEX TERMS 
[Intervention Review]

\section{Antibiotic therapy for preventing infections in people with acute stroke}

Jan-Dirk Vermeij ${ }^{1}$, Willeke F Westendorp ${ }^{1}$, Diederik WJ Dippel2 ${ }^{2}$, Diederik van de Beek ${ }^{1}$, Paul J Nederkoorn ${ }^{1}$

1Department of Neurology, Academic Medical Centre, University of Amsterdam, Amsterdam, Netherlands. 2Erasmus MC University Medical Center, Rotterdam, Netherlands

Contact address: Paul J Nederkoorn, Department of Neurology, Academic Medical Centre, University of Amsterdam, PO Box 22660, Amsterdam, 1100 DD, Netherlands.p.j.nederkoorn@amc.uva.nl.

Editorial group: Cochrane Stroke Group.

Publication status and date: New search for studies and content updated (conclusions changed), published in Issue 1, 2018.

Citation: Vermeij JD, Westendorp WF, Dippel DWJ, van de Beek D, Nederkoorn PJ. Antibiotic therapy for preventing infections in people with acute stroke. Cochrane Database of Systematic Reviews 2018, Issue 1. Art. No.: CD008530. DOI: 10.1002/14651858.CD008530.pub3.

Copyright @ 2018 The Cochrane Collaboration. Published by John Wiley \& Sons, Ltd.

\section{A B S T R A C T}

\section{Background}

Stroke is the main cause of disability in high-income countries and ranks second as a cause of death worldwide. Infections occur frequently after stroke and may adversely affect outcome. Preventive antibiotic therapy in the acute phase of stroke may reduce the incidence of infections and improve outcome. In the previous version of this Cochrane Review, published in 2012, we found that antibiotics did reduce the risk of infection but did not reduce the number of dependent or deceased patients. However, included studies were small and heterogeneous. In 2015, two large clinical trials were published, warranting an update of this Review.

\section{Objectives}

To assess the effectiveness and safety of preventive antibiotic therapy in people with ischaemic or haemorrhagic stroke. We wished to determine whether preventive antibiotic therapy in people with acute stroke:

- reduces the risk of a poor functional outcome (dependency and/or death) at follow-up;

- reduces the occurrence of infections in the acute phase of stroke;

- reduces the occurrence of elevated body temperature (temperature $\geq 38^{\circ} \mathrm{C}$ ) in the acute phase of stroke;

- reduces length of hospital stay; or

- leads to an increased rate of serious adverse events, such as anaphylactic shock, skin rash, or colonisation with antibiotic-resistant microorganisms.

\section{Search methods}

We searched the Cochrane Stroke Group Trials Register (25 June 2017); the Cochrane Central Register of Controlled Trials (CENTRAL; 2017, Issue 5; 25 June 2017) in the Cochrane Library; MEDLINE Ovid (1950 to 11 May 2017), and Embase Ovid (1980 to 11 May 2017 ). In an effort to identify further published, unpublished, and ongoing trials, we searched trials and research registers, scanned reference lists, and contacted trial authors, colleagues, and researchers in the field.

\section{Selection criteria}

Randomised controlled trials (RCTs) of preventive antibiotic therapy versus control (placebo or open control) in people with acute ischaemic or haemorrhagic stroke.

\section{Data collection and analysis}

Two review authors independently selected articles and extracted data; we discussed and resolved discrepancies at a consensus meeting with a third review author. We contacted study authors to obtain missing data when required. An independent review author assessed risk of bias using the Cochrane 'Risk of bias' tool. We calculated risk ratios (RRs) for dichotomous outcomes, assessed heterogeneity amongst included studies, and performed subgroup analyses on study quality. 


\section{Main results}

We included eight studies involving 4488 participants. Regarding quality of evidence, trials showed differences in study population, study design, type of antibiotic, and definition of infection; however, primary outcomes among the included studies were consistent. Mortality rate in the preventive antibiotic group was not significantly different from that in the control group (373/2208 (17\%) vs 360/2214 (16\%); RR $1.03,95 \%$ confidence interval (CI) 0.87 to 1.21 ; high-quality evidence). The number of participants with a poor functional outcome (death or dependency) in the preventive antibiotic therapy group was also not significantly different from that in the control group (1158/2168 (53\%) vs $1182 / 2164$ (55\%); RR $0.99,95 \% \mathrm{Cl} 0.89$ to 1.10 ; moderate-quality evidence). However, preventive antibiotic therapy did significantly reduce the incidence of 'overall' infections in participants with acute stroke from $26 \%$ to $19 \%$ (408/2161 (19\%) vs 558/2156 (26\%); RR 0.71, $95 \% \mathrm{Cl} 0.58$ to 0.88 ; high-quality evidence). This finding was highly significant for urinary tract infections ( $81 / 2131(4 \%)$ vs $204 / 2126(10 \%)$; RR $0.40,95 \% \mathrm{Cl} 0.32$ to 0.51 ; high-quality evidence), whereas no preventive effect for pneumonia was found (222/2131 (10\%) vs $235 / 2126$ (11\%); RR $0.95,95 \%$ Cl 0.80 to 1.13; high-quality evidence). No major side effects of preventive antibiotic therapy were reported. Only two studies qualitatively assessed the occurrence of elevated body temperature; therefore, these results could not be pooled. Only one study reported length of hospital stay.

\section{Authors' conclusions}

Preventive antibiotics had no effect on functional outcome or mortality, but significantly reduced the risk of 'overall' infections. This reduction was driven mainly by prevention of urinary tract infection; no effect for pneumonia was found.

\section{PLAIN LANGUAGE SUMMARY}

\section{Antibiotic therapy for preventing infections in people with acute stroke}

\section{Review question}

Does preventive antibiotic therapy in people with acute stroke reduce the risk of dependency and death at follow-up, and does it reduce the infection rate?

\section{Background}

Stroke is the main cause of disability in high-income countries and ranks second as a cause of death worldwide. It is often followed by complications, especially infections, which occur in approximately $30 \%$ of people who have had a stroke. The occurrence of an infection may adversely affect clinical outcome after stroke. Preventive antibiotic therapy may reduce the number of infections, thereby improving stroke outcome.

\section{Search date}

This review is current to May 2017.

\section{Study characteristics}

We included eight studies on preventive antibiotic therapy, with a total of 4488 people with stroke: 2230 participants were randomised to preventive antibiotic therapy, and 2258 to control. The mean age of participants in the preventive antibiotics group was 74.2 years, and in the control group 74.8 years. In both groups, the percentage of men was 52\%. Study interventions differed in all eight studies; in two studies, trialists selected the (type of) antibiotic according to local antibiotic policy, with the aim of treating pneumonia.

\section{Key results}

Preventive antibiotic treatment did not reduce the risk of dependency or death.

However, preventive antibiotic therapy did significantly reduce the occurrence of 'overall' infections from 26\% to $19 \%$. Regarding type of infection, findings were highly significant for urinary tract infections ( $4 \%$ vs $10 \%)$ but showed no effect on pneumonia (10\% vs $11 \%)$.

No major side effects of preventive antibiotic therapy were reported.

\section{Quality of the evidence}

It has become possible to draw first 'overall' conclusions on the net effect of preventive antibiotic therapy in stroke; however, the decision of whether to use preventive antibiotic therapy in acute stroke should be reached with care. Studies were heterogeneous, and despite the large numbers of participants, results from a total of eight studies are limited. In two of these studies, risk of bias was considered to be high for three out of six criteria. Overall, reviewers considered the quality of evidence for the main outcomes of this review - looking at 'any' preventive antibiotic therapy, in 'any' dose, at any length of treatment - as high to moderate. 


\section{SUMMARY OF FINDINGS}

\section{Summary of findings for the main comparison.}

Preventive antibiotic therapy compared with placebo and/or conventional management in acute stroke

Patient or population: patients with acute ischaemic or haemorrhagic stroke

Setting: acute stroke management

Intervention: preventive antibiotic therapy for systemic use, at any dose or length of treatment

Comparison: placebo and/or conventional acute stroke management

\begin{tabular}{|c|c|c|c|c|c|c|}
\hline \multirow[t]{2}{*}{ Outcomes } & \multicolumn{2}{|l|}{ Absolute risk } & \multirow{2}{*}{$\begin{array}{l}\text { Relative effect } \\
(95 \% \mathrm{CI})\end{array}$} & \multirow{2}{*}{$\begin{array}{l}\text { No. of partici- } \\
\text { pants } \\
\text { (studies) }\end{array}$} & \multirow{2}{*}{$\begin{array}{l}\text { Quality of the } \\
\text { evidence } \\
\text { (GRADE) }\end{array}$} & \multirow[t]{2}{*}{ Comments } \\
\hline & $\begin{array}{l}\text { Risk with placebo } \\
\text { and/or conventional } \\
\text { management }\end{array}$ & $\begin{array}{l}\text { Risk with preven- } \\
\text { tive antibiotic } \\
\text { treatment }\end{array}$ & & & & \\
\hline \multirow[t]{2}{*}{ Case fatality at the end of follow-up } & \multicolumn{2}{|l|}{ Study population } & \multirow{2}{*}{$\begin{array}{l}\text { RR } 1.03 \\
\text { (0.87 to } 1.21)\end{array}$} & \multirow{2}{*}{$\begin{array}{l}4422 \\
(8)\end{array}$} & \multirow{2}{*}{$\begin{array}{l}\oplus \oplus \oplus \oplus \\
\text { high } a, b\end{array}$} & \\
\hline & 163 per 1000 & 169 per 1000 & & & & \\
\hline \multirow{2}{*}{$\begin{array}{l}\text { Poor functional outcome at the end } \\
\text { of follow-up }\end{array}$} & \multicolumn{2}{|l|}{ Study population } & \multirow{2}{*}{$\begin{array}{l}\text { RR } 0.99 \\
(0.89 \text { to } 1.10)\end{array}$} & \multirow{2}{*}{$\begin{array}{l}4332 \\
(7)\end{array}$} & \multirow{2}{*}{$\begin{array}{l}\oplus \oplus \oplus \oplus \\
\text { moder- } \\
\text { ate }\end{array}$} & \\
\hline & 547 per 1000 & 535 per 1000 & & & & \\
\hline \multirow{2}{*}{$\begin{array}{l}\text { Number of infections at the end of } \\
\text { follow-up }\end{array}$} & \multicolumn{2}{|l|}{ Study population } & \multirow{2}{*}{$\begin{array}{l}\text { RR } 0.71 \\
(0.58 \text { to } 0.88)\end{array}$} & \multirow{2}{*}{$\begin{array}{l}4317 \\
(7)\end{array}$} & \multirow{2}{*}{$\begin{array}{l}\oplus \oplus \oplus \oplus \\
\text { higha,b,f }\end{array}$} & \\
\hline & 259 per 1000 & 189 per 1000 & & & & \\
\hline $\begin{array}{l}\text { Number of UTIs at the end of fol- } \\
\text { low-up }\end{array}$ & 96 per 1000 & 39 per 1000 & $\begin{array}{l}\text { RR } 0.40 \\
(0.32 \text { to } 0.51)\end{array}$ & $\begin{array}{l}4257 \\
(6)\end{array}$ & $\begin{array}{l}\oplus \oplus \oplus \oplus \\
\text { high }^{a}, \mathrm{~b}\end{array}$ & \\
\hline \multirow{2}{*}{$\begin{array}{l}\text { Number of pneumonias at the end of } \\
\text { follow-up }\end{array}$} & \multicolumn{2}{|l|}{ Study population } & RR 0.95 & 4257 & $\oplus \oplus \oplus \oplus$ & \\
\hline & 111 per 1000 & 105 per 1000 & (0.80 to 1.13$)$ & (6) & & \\
\hline $\begin{array}{l}\text { Occurrence of elevated body tem- } \\
\text { perature }\end{array}$ & \multicolumn{6}{|c|}{ Insufficient data. Assessed qualitatively in only 2 studies } \\
\hline Rate of serious adverse events & \multicolumn{6}{|c|}{ No major side effects of preventive antibiotic therapy were reported. } \\
\hline
\end{tabular}


${ }^{*}$ The absolute risk is calculated using the absolute numbers of events in both study arms.

Cl: confidence interval; RR: risk ratio; UTIs: urinary tract infections.

GRADE Working Group grades of evidence.

High quality: Further research is very unlikely to change our confidence in the estimate of effect.

Moderate quality: Further research is likely to have an important impact on our confidence in the estimate of effect and may change the estimate.

Low quality: Further research is very likely to have an important impact on our confidence in the estimate of effect and is likely to change the estimate.

Very low quality: We are very uncertain about the estimate.

a Large number of included studies, large number of participants, and small confidence interval (ultimately low risk of bias). Good applicability in clinical practice.

$b$ Limited publication bias cannot be excluded, as funnel plots for primary outcomes were skewed at the base, towards good outcomes.

'Regarding risk of bias of individual included studies, more than two of the included studies scored at least one criterion of 'unclear' and/or 'high' risk of bias on the Cochrane 'Risk of bias' summary (Figure 1). However, the effect on primary outcomes was consistent among studies with 'low' risk of bias.

dRegarding consistency of effect, heterogeneity was substantial $\left(I^{2}=79 \%\right)$. However, overall effect estimates were precise. Stratifying for included studies with 'low risk of bias' resulted in loss of heterogeneity $\left(I^{2}=4 \%\right)$ and did not affect outcomes. Therefore, we did not downgrade the quality of evidence.

eDowngraded owing to multiple remarks on GRADE considerations, despite the fact that all remarks can be explained and rectified.

fRegarding consistency of effect, heterogeneity was moderate $\left(I^{2}=56 \%\right)$. However, overall effect estimates were precise. Therefore, we did not downgrade the quality of evidence. 
Figure 1. Risk of bias summary: review authors' judgements about each risk of bias item for each included study, using the Cochrane 'Risk of bias' tool. '+' is defined as low risk of bias, '-' as high risk of bias, '?' as unclear risk of bias.

\begin{tabular}{|c|c|c|c|c|c|c|}
\hline & 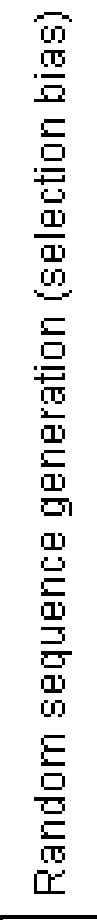 & 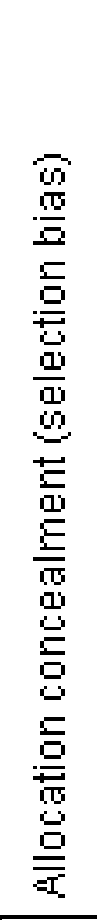 & 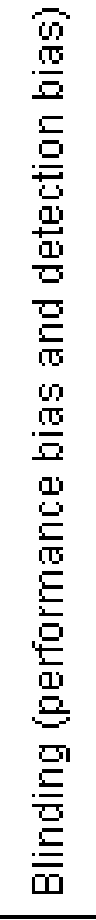 & 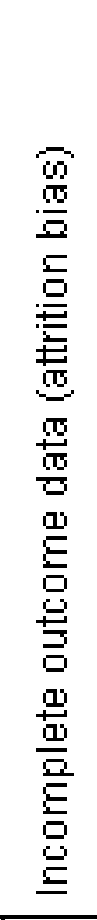 & 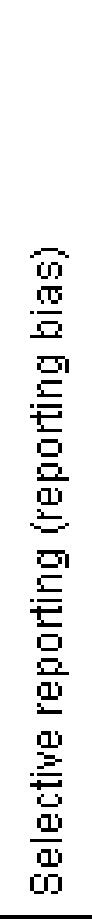 & 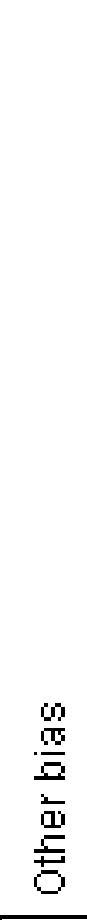 \\
\hline Chamorro 2005 & + & + & 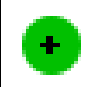 & + & $\odot$ & + \\
\hline De Falco 1998 & $?$ & $?$ & - & - & $\odot$ & + \\
\hline Harms 2008 & + & + & + & - & $\odot$ & + \\
\hline Kalra 2015 & + & + & + & + & + & + \\
\hline Lampl 2007 & & - & + & $\odot$ & + & + \\
\hline Schwarz 2008 & + & + & - & + & + & + \\
\hline UIm 2016 & + & + & + & + & + & + \\
\hline Westendorp 2015 & + & + & + & + & + & + \\
\hline
\end{tabular}




\section{B A C K G R O U N D}

Stroke is a main cause of disability and death worldwide in both high-income and developing countries. Infection is a common complication in the acute phase after stroke, affecting approximately $30 \%$ of these patients; in particular pneumonia and urinary tract infections (Westendorp 2011).

The increased risk of infection can be attributed to different factors. First, infections are associated with a person's clinical condition. Older people with more severe stroke experience infections more frequently. Also, people with swallowing disturbances with subsequent aspiration are at increased risk of pneumonia (Kammersgaard 2001; Lee 2007; Martino 2005; Yilmaz 2007). Second, use of invasive procedures, such as urinary catheterisation or mechanical ventilation, is associated with the occurrence of infections (Stott 2009; Walter 2007). In addition, acute stroke may lead to stroke-induced immunodepression - a systemic antiinflammatory response that is thought to increase vulnerability to infection amongst people in the acute phase of stroke (Chamorro 2006; Emsley 2008; Haeusler 2008).

The effect of infection on stroke outcome remains uncertain. Several studies showed that infection was associated with poor functional outcome and mortality (Finlayson 2011; Popović 2013; Vermeij 2009), whereas other studies found that infections were merely a marker of stroke severity that had no effect on clinical outcome (Vargas 2006).

Different interventions have been proposed to prevent infection after stroke, such as use of a protocol by trained nurses for managing people with dysphagia (Carnaby 2006), as well as avoidance of urinary catheters. Most of these are only partially effective. In a previous Cochrane meta-analysis, we showed that the incidence of infection could be significantly reduced (from 36\% to $22 \%$ ) by preventive antibiotics in the acute phase after stroke (Westendorp 2012). However, effects on stroke outcome remained unclear because included studies were small and heterogeneous. To establish with certainty whether preventive antibiotic therapy has a place in the treatment of acute stroke, large randomised controlled trials (RCTs) were needed.

Two large clinical trials published in 2015 warranted an update of this review (Kalra 2015; Westendorp 2015). This meta-analysis aims to assess current knowledge on the effect of preventive antibiotic therapy on functional outcome after stroke, incidence of infections, and length of hospital stay, along with the number of adverse events.

\section{Description of the condition}

Acute ischaemic or haemorrhagic stroke.

\section{Description of the intervention}

Oral or parenteral preventive antibiotic treatment, of any duration, started after onset of stroke symptoms in people without infection at presentation.

\section{How the intervention might work}

Infections occurring within seven days after stroke are thought to be associated with poor outcome, independent of stroke severity and other prognostic factors (Finlayson 2011; Popović 2013; Vermeij
2009; Westendorp 2012). Preventive antibiotic therapy may prevent infections in people with acute stroke, resulting in a better functional outcome and lower case fatality rates.

Preventive antibiotic treatment may also produce adverse effects such as anaphylactic shock, skin rash, gastrointestinal complications, neurotoxicity (epileptic seizures), ototoxicity (damage to the ear by a toxin), and nephrotoxicity (the poisonous effect of some substances on the kidneys). Besides, antibiotic treatment may lead to colonisation with antibiotic-resistant microorganisms. As a consequence, patients may develop infections that are difficult to treat.

\section{Why it is important to do this review}

A previous meta-analysis showed that preventive antibiotic use resulted in a significant reduction in infections (Westendorp 2012). Several studies have suggested an association between the occurrence of an infection after stroke and poor outcome. Therefore, preventive use of antibiotic therapy could potentially improve stroke outcome.

\section{O B JECT IVES}

To assess the effectiveness and safety of preventive antibiotic therapy for people with ischaemic or haemorrhagic stroke. We wished to determine whether preventive antibiotic therapy for people with acute stroke:

- reduces the risk of a poor functional outcome (dependency and/ or death) at follow-up;

- reduces the occurrence of infections in the acute phase of stroke;

- reduces the occurrence of elevated body temperature (temperature $\geq 38^{\circ} \mathrm{C}$ ) in the acute phase of stroke;

- reduces length of hospital stay; or

- leads to an increased rate of serious adverse events, such as anaphylactic shock, skin rash, or colonisation with antibioticresistant micro-organisms.

\section{METHODS}

\section{Criteria for considering studies for this review}

\section{Types of studies}

We searched for all randomised controlled trials (RCTs) of preventive antibiotic therapy versus control (placebo or open control).

\section{Types of participants}

People with acute ischaemic or haemorrhagic stroke, aged 18 years or older. We included trials that did not differentiate between ischaemic and haemorrhagic stroke by computed tomography (CT) or magnetic resonance imaging (MRI) before inclusion in the trial, on the basis that $75 \%$ to $90 \%$ of strokes are ischaemic and occur in predominantly white populations.

\section{Types of interventions}

Preventive antibiotic therapy for systemic use (oral, intramuscular, or intravenous administration) at any dose or length of treatment, starting after stroke onset, versus placebo or open control. 


\section{Types of outcome measures}

At least, investigators had to record the incidence of infection or mortality for studies to be included.

\section{Primary outcomes}

Functional status of the patient. Since the aim of antibiotic treatment should be to prevent disability, we assessed two outcome parameters, both assessing dependency in activities of daily living, scored at the end of follow-up (either end of treatment, or one to three months after the initial event). These were preferably measured with the modified Rankin Scale (mRS), or otherwise the Barthel Index (BI).

Our main outcome parameters were:

- case fatality (mRS 6); and

- 'poor functional outcome' (death or dependency; preferably $\mathrm{mRS} \geq 3$ )

\section{Secondary outcomes}

- occurrence of 'any infection' in the acute phase of stroke (throughout the manuscript called 'overall' infections to make a distinction with (sub)types of infection)

- occurrence of urinary tract infections in the acute phase of stroke

- occurrence of pneumonia in the acute phase of stroke

- occurrence of elevated body temperature (temperature $\geq 38^{\circ} \mathrm{C}$ ) in the acute phase of stroke

- length of hospital stay

- occurrence of adverse events likely to be related to antibiotic therapy

\section{Search methods for identification of studies}

See the 'Specialized Register' section in the Cochrane Stroke Group module. We searched for trials published in all languages and arranged translation of trial reports when required.

\section{Electronic searches}

We searched the Trials Register of the Cochrane Stroke Group and the Cochrane Central Register of Controlled Trials (CENTRAL; 2017, Issue 5) in the Cochrane Library (last searched 25 June 2017) (Appendix 1); MEDLINE Ovid (1950 to 11 May 2017) (Appendix 2); and Embase Ovid (1980 to 11 May 2017) (Appendix 3).

We developed the MEDLINE Ovid and Embase Ovid search strategies with the help of the Cochrane Stroke Group's Information Specialist and adapted them for use with the other databases.

In an effort to identify additional published, unpublished, and ongoing trials, we searched the following trials and research registers (24 August 2017) (Appendix 4). We conducted broad searches to ensure that no trials were missed.

- ClinicalTrials.gov (www.clinicaltrials.gov).

- ISRCTN Registry (www.isrctn.com).

- Stroke Trials Registry (www.strokecenter.org/trials).

- World Health Organization (WHO) Registry Platform (apps.who.int/trialsearch).

\section{Searching other resources}

We scanned the reference lists of relevant articles and contacted trial authors, colleagues, and researchers in the field.

\section{Data collection and analysis}

\section{Selection of studies}

Two review authors (JDV, WW) independently screened the titles and abstracts of studies identified through database searches, and excluded obviously irrelevant articles. We obtained the full text of remaining articles and independently selected studies meeting the inclusion criteria for this review. We resolved disagreements by discussion and by consultation with a third review author (PJN), if necessary.

\section{Data extraction and management}

Two review authors (JDV, WW) independently extracted and recorded trial data on specially designed forms, and subsequently cross-checked the data. We discussed and resolved discrepancies at a consensus meeting with a third review author (PJN). We collected the following data from identified studies: study design, inclusion and exclusion criteria, participant characteristics, intervention characteristics, and outcome and complication measures. Participant characteristics included age, sex, stroke type, stroke severity, and the number of dysphagic patients. Intervention characteristics included type, dosage, and duration of the intervention; co-treatment with antipyretic medication; time from symptom onset to intervention (with intended dichotomisation at 24 hours from onset); and the number of participants with incomplete treatment. Outcome measures included body temperature in the acute phase of stroke, occurrence of infections, types of infection, elapsed time from start of treatment to occurrence of infection, data on functional outcome, length of hospital stay, and death. Complication measures consisted of complications and adverse events noted during follow-up, including incidence of colonisation with antibiotic-resistant microorganisms.

\section{Assessment of risk of bias in included studies}

One review author (DWJD) assessed the risk of bias for each study, except for Westendorp 2015 owing to co-authorship, which was assessed by an external observer (BvdV).

For each study, we evaluated methodological quality using the Cochrane 'Risk of bias' tool. We rated each criterion as having 'low' risk of bias, 'high' risk of bias, or 'unclear' risk of bias, indicating lack of information or uncertainty over the potential for bias (Higgins 2016). We assessed:

- adequacy of sequence generation;

- allocation concealment;

- blinding of participants and personnel;

- blinding of outcome assessment;

- Incomplete outcome data;

- selective reporting; and

- other sources of bias.

\section{Measures of treatment effect}

For dichotomous outcomes, we calculated a weighted estimate of treatment effects across trials using the risk ratio (RR). When using 
continuous scales of measurement to assess effects of treatment, we used the mean difference (MD).

\section{Unit of analysis issues}

We calculated a weighted estimate of the typical treatment effect across trials (RR) by using a fixed-effect model and Review Manager 5.3 (RevMan 2014). However, in case of heterogeneity of treatment effects, we used the random-effects model to assess the overall treatment effect.

We did not expect to find any trials with a cross-over design. For cluster-randomised trials, we considered effect estimates (RR) with adjustment for a cluster effect.

\section{Dealing with missing data}

In case of missing data, for example when mRS or BI scores were not available, we contacted the corresponding publication author to request follow-up data that were as complete as possible for all randomised participants.

\section{Assessment of heterogeneity}

We used tests for heterogeneity between trial results along with the Cochrane $\mathrm{Q}$ statistic and the $\mathrm{I}^{2}$ statistic (percentage of total variation across studies due to heterogeneity). We considered values exceeding $50 \%$ as representing substantial heterogeneity. We also assessed heterogeneity qualitatively by comparing the population and design of each study for the primary outcomes using a sensitivity analysis.

\section{Assessment of reporting biases}

We used funnel plots to assess reporting bias and assessed funnel plots qualitatively.

\section{Data synthesis}

\section{GRADE and 'Summary of findings' table}

We created Summary of findings for the main comparison using the following outcomes.

- Primary outcome measure: case fatality at the end of follow-up.

- Primary outcome measure: poor functional outcome at the end of follow-up.

- Secondary outcome measure: number of ('overall') infections at the end of follow-up.

- Secondary outcome measure: number of urinary tract infections at the end of follow-up.

- Secondary outcome measure: number of pneumonias at the end of follow-up.

- Secondary outcome measure: occurrence of elevated body temperature.

- Secondary outcome measure: number of serious adverse events.

We assessed the overall quality of evidence for main outcomes (the two primary outcomes and the secondary outcome 'any infection', which can be considered a mediator) by taking into account the five GRADE considerations: risk of bias, consistency of effect, imprecision, indirectness, and publication bias (Higgins 2016). We also applied GRADE criteria for Summary of findings for the main comparison.

\section{Subgroup analysis and investigation of heterogeneity}

We aimed to conduct the following subgroup analyses.

- Stroke severity.

- Early (within 24 hours) versus late (after 24 hours) start of treatment after stroke.

\section{Sensitivity analysis}

When we found substantial heterogeneity on efficacy analysis, we explored heterogeneity by stratifying for risk of bias and including only studies with 'low' risk of bias. We therefore used the Cochrane 'Risk of bias' tool and assessed the risk of bias of each individual study. We considered studies at 'moderate' risk of bias if we found more than two items to be at 'high' risk or 'unclear' risk. We considered studies at 'low' risk of bias if we scored fewer than two items as having 'high' risk or 'unclear' risk in the 'Risk of bias' summary.

Regarding primary outcomes, we also performed a sensitivity analysis on study design: placebo and/or double-blinded versus open-label trial.

\section{RES U LTS}

\section{Description of studies}

See Characteristics of included studies.

\section{Results of the search}

Through electronic searching, we found 830 MEDLINE Ovid and 3792 Embase Ovid abstracts. We deliberately used broad search criteria for trials and research registers and found one extra study in CENTRAL. We identified three additional studies as initially applicable by searching other trials and research registers. We assessed 15 full-text articles for eligibility, of which we excluded eight before qualitative synthesis (one appeared to be a double hit, two were review articles, and five articles appeared to be unusable after we considered the paper in greater detail: one was a conference abstract of a long-term follow-up of an earlier study that had not been published, one was a conference abstract on ventilator-associated pneumonia, one included only people with indwelling catheters, and two did not apply the study design needed to be eligible). In addition to the remaining seven studies, we identified one extra trial that had just been completed. We received permission to include the data in this meta-analysis. After qualitative synthesis, we included all eight studies in the metaanalysis. We have presented a PRISMA flow chart of study selection in Figure 2. 
Figure 2. Study flow diagram.

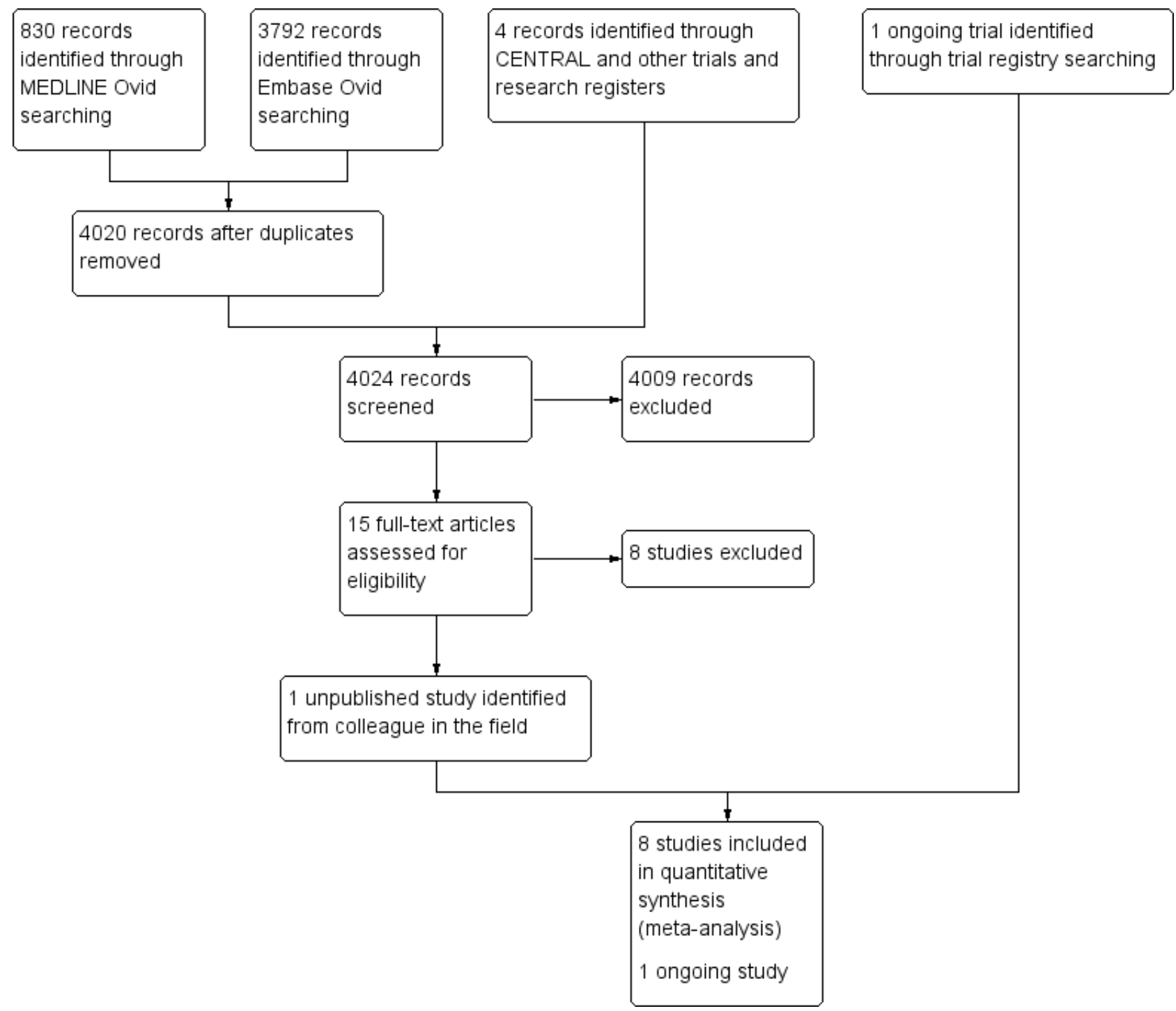

\section{Included studies}

We found eight studies eligible for inclusion in the metaanalysis (Chamorro 2005; De Falco 1998; Harms 2008; Kalra 2015; Lampl 2007; Schwarz 2008; Ulm 2016; Westendorp 2015). These studies included 4488 participants in total: 2230 participants were randomised to preventive antibiotic therapy, and 2258 were randomised to control groups. In the control groups, 186 participants were randomised to placebo (Chamorro 2005; Harms 2008; Lampl 2007), and 2072 participants to conventional management (De Falco 1998; Kalra 2015; Schwarz 2008; Ulm 2016; Westendorp 2015). Sample size calculation was performed in six studies (Chamorro 2005; Harms 2008; Kalra 2015; Lampl 2007; Ulm 2016; Westendorp 2015): One of these studies was terminated prematurely after the first 130 participants were analysed, because no effect was expected (Chamorro 2005), and one study was terminated earlier than the initial sample size after an amendment was made to the primary outcome (from dichotomous to ordinal regression), mainly owing to insufficient funding (Westendorp 2015). All studies included adult participants; one study included participants of all ages (De Falco 1998). Three studies included people with ischaemic and haemorrhagic stroke (Chamorro 2005; Kalra 2015; Westendorp 2015); all other studies only included people with ischaemic stroke.

The mean age in the preventive antibiotics group was 74.2 years, and in the control group 74.8 years. In both treatment groups, the percentage of men was $52 \%$. Seven studies reported baseline median stroke severity scores on the National Institutes of Health Stroke Scale (NIHSS) (Chamorro 2005; Harms 2008; Kalra 2015; Lampl 2007; Schwarz 2008; Ulm 2016; Westendorp 2015); these scores ranged from 5 to 17 in the preventive antibiotics group, and from 5 to 15.5 in the control group. One study reported stroke severity on the Canadian Neurological Scale (CNS), with median CNS score of 4.5 (standard deviation (SD) 2.3) in the preventive antibiotics group versus 4.1 (SD 2.1) in the control group (De Falco 1998). One study excluded people with swallowing difficulties at presentation (Lampl 2007), whereas another study used swallowing difficulties as an inclusion criterion (Kalra 2015). One other study reported the number of people with dysphagia (Westendorp 2015). 
Study intervention differed in all eight studies: fluoroquinolones in two studies - levofloxacin in Chamorro 2005 and moxifloxacin in Harms 2008; a tetracycline (minocycline) in Lampl 2007; a bètalactam antibiotic in Westendorp 2015; a combination of a bètalactam antibiotic and a bèta-lactamase inhibitor in Schwarz 2008; and penicillin in De Falco 1998. In two studies, the choice of the (type of) antibiotic was made according to the local antibiotic policy of the participating centre (Kalra 2015; Ulm 2016). The aim of both of these studies was to treat (stroke-associated) pneumonia.

Route of administration was intravenous in four studies (Chamorro 2005; Harms 2008; Schwarz 2008; Westendorp 2015); oral in one (Lampl 2007); and intramuscular in one (De Falco 1998). Investigators in two studies chose the antibiotic and route of administration according to local policy (Kalra 2015; Ulm 2016). Amongst studies with predescribed antibiotics, one study did not report dosage (De Falco 1998). Six studies required that participants had to be included within 24 hours of stroke onset (Chamorro 2005; De Falco 1998; Harms 2008; Lampl 2007; Schwarz 2008; Westendorp 2015); and two studies required enrolment within 48 hours (Kalra 2015; Ulm 2016). The duration of (predescribed) antibiotic therapy ranged from three to five days, and one study did not report this information (De Falco 1998). Two studies described mean elapsed time from start of symptoms to intervention for both treatment groups. In these two studies, 141 participants were included in the preventive antibiotics group with a mean time to treatment of 13.3 hours; 146 participants were included in the control group with mean time to treatment of 12.2 hours (Chamorro 2005; Lampl 2007). One study described time to treatment for the total group of participants as 24 hours (Harms 2008). Completeness of treatment was described in four studies, with a total of 3970 participants; treatment was incomplete in $2.8 \%$ (56 out of 1976) of participants in the preventive antibiotic therapy group (Chamorro 2005; Harms 2008; Kalra 2015; Westendorp 2015). Ulm 2016 provided ultrasensitive procalcitonin (PCTus)-guided antibiotic treatment and reported $65 \%$ adherence to PCT guidance. Three studies did not provide information on completeness of treatment (De Falco 1998; Lampl 2007; Schwarz 2008). No studies provided data on co-treatment with antipyretic medication.

Case fatality was reported as a primary outcome in one study (De Falco 1998); seven studies reported case fatality as a secondary outcome (Chamorro 2005; Harms 2008; Kalra 2015; Lampl 2007; Schwarz 2008; Ulm 2016; Westendorp 2015). All eight studies presented data on functional outcome; however, outcome scales and duration of follow-up varied. Investigators used three different scales: mRS in six studies (Chamorro 2005; Kalra 2015; Lampl 2007; Schwarz 2008; Ulm 2016; Westendorp 2015); BI in five studies (Chamorro 2005; De Falco 1998; Harms 2008; Lampl 2007; Ulm 2016); and CNS in one study (De Falco 1998). Three studies did not report the number of dependent participants (Chamorro 2005; De Falco 1998; Lampl 2007). Attempts to collect additional information from the study authors failed in one case and succeeded in two (Chamorro 2005; Lampl 2007). Dependency was defined as $\mathrm{BI}<60$ (Harms 2008) or mRS score $\geq 3$ (Chamorro 2005; Kalra 2015; Schwarz 2008; Ulm 2016; Westendorp 2015). Included studies assessed case fatality and functional outcomes during different follow-up periods; one study reported case fatality during hospital stay (De Falco 1998); six studies reported both case fatality and functional outcomes at three months (Chamorro 2005; Kalra 2015; Lampl 2007; Schwarz 2008; Ulm 2016; Westendorp 2015); and one study at six months (Harms 2008).
Infection rate was reported as a primary outcome in two studies (Chamorro 2005; Harms 2008), with varying duration of follow-up (seven and 11 days). In five studies, infection rate was presented as a secondary outcome: two studies reported infection rate during hospital stay (De Falco 1998; Westendorp 2015), one study during seven days (Ulm 2016), one study during an observation period of 10 days (Schwarz 2008), and one study during 90 days (Kalra 2015). One study did not report infection rate (Lampl 2007). Type of infection was specified in five of the seven studies that reported infection rate (Harms 2008; Kalra 2015; Schwarz 2008; Ulm 2016; Westendorp 2015), one study reported only the pneumonia rate (De Falco 1998). One study did not specify the type of infection (Chamorro 2005). Definitions used for the diagnosis of infection differed substantially between studies; we have provided these in Appendix 5.

Two studies reported the occurrence of elevated body temperature (Harms 2008; Schwarz 2008). One study reported data on length of hospital stay (Kalra 2015), none on the incidence of opportunistic infections in the two treatment groups. Five studies reported the incidence of adverse events (Harms 2008; Kalra 2015; Schwarz 2008; Ulm 2016; Westendorp 2015). Three studies reported data on the occurrence of colonisation with antibiotic-resistant microorganisms on day 11 after stroke (Harms 2008; Kalra 2015; Westendorp 2015).

We identified one ongoing trial (ISRCTN82217627). This study aims to assess functional outcome and infection rate amongst participants allocated in a $2 \times 2 \times 2$ factorial design to any combination of metoclopramide (10 $\mathrm{mg}$ three times daily), intravenous ceftriaxone (2000 mg once daily), or paracetamol (1000 $\mathrm{mg}$ four times daily), or to usual care.

\section{Excluded studies}

We excluded no studies after qualitative synthesis of manuscript data.

\section{Risk of bias in included studies}

Figure 1 shows a summary of the risk of bias in all included studies. We have provided a 'Risk of bias' table for each study in the Characteristics of included studies section.

\section{Allocation}

A randomised sequence generation was a requirement for inclusion in the meta-analysis and therefore was present in all studies. However, one study randomised by using the eighth number on the participant's identity card. This can be considered a random number but might also be considered inferior, because treatment allocation was not concealed (Lampl 2007). One study did not specify allocation concealment (De Falco 1998). The other six studies sufficiently described allocation concealment.

\section{Blinding}

Two studies used a double-blind design (Chamorro 2005; Harms 2008); the other six studies used an open-label design. In three of these open-label studies, outcomes were assessed blindly by trial office researchers masked to allocation (Kalra 2015; Ulm 2016; Westendorp 2015). In one study, outcomes were reported to be assessed blindly, although the method of blinding was not specified (Lampl 2007). One study described blinded assessment of infections but did not describe blinded assessment of secondary 
outcomes such as mRS (Schwarz 2008). One study did not describe blinding (De Falco 1998).

\section{Incomplete outcome data}

In three studies, incomplete outcome data were completely addressed: One study had no losses to follow-up at all (Schwarz 2008), and two studies described losses to follow-up in detail for primary or secondary outcomes, or both (Kalra 2015; Westendorp 2015). Three studies provided incomplete insight on missing data: for one study, this can be explained by the fact that the data are not yet published and secondary outcomes currently are not known (Ulm 2016); in another study, researchers assessed the primary outcome for all participants but did not describe the number of participants according to treatment allocation for the secondary outcomes (Chamorro 2005); in the third study, trial authors reported no further details on the (seven) participants lost to follow-up (Harms 2008). Two studies did not describe completeness of follow-up and outcome assessment at all (De Falco 1998; Lampl 2007).

\section{Selective reporting}

Five studies performed an intention-to-treat (ITT) analysis (Chamorro 2005; Kalra 2015; Lampl 2007; Schwarz 2008; Westendorp 2015). Two studies performed both ITT and perprotocol analyses (Harms 2008; Ulm 2016). One study performed a per-protocol analysis alone (De Falco 1998).

\section{Other potential sources of bias}

Data show no other potential sources of bias.

\section{Effects of interventions}

See: Summary of findings for the main comparison

\section{Primary outcomes}

The overall number of participants who died was 373 of 2208 (17\%) in the preventive antibiotics group versus 360 of $2214(16 \%)$ in the control group (RR $1.03,95 \% \mathrm{Cl} 0.87$ to 1.21 ; high-quality evidence) (Analysis 1.1). Data show no substantial heterogeneity $\left(P=0.31 ; I^{2}\right.$ $=15 \%)$.

The number of participants with a poor functional outcome (death or dependency) was 1158 of $2168(53 \%)$ in the preventive antibiotics group versus 1182 of 2164 (55\%) in the control group (RR $0.99,95 \% \mathrm{Cl} 0.89$ to 1.10 ; moderate-quality evidence) (Analysis 1.2). Substantial heterogeneity was present $\left(P<0.0001 ;\left.\right|^{2}=79 \%\right)$ and can be noted in the funnel plots (Figure 3; Figure 4). One study was not included in this analysis: De Falco 1998 did not report the number of dependent participants at the end of follow-up. In this study, mean scores for outcome of both treatment groups were reported and showed a better functional outcome in the preventive antibiotics group, with a mean $\mathrm{BI}$ of 38.2 (SD 32.4) in the preventive antibiotics group versus 21.8 (SD 27.6) in the control group.

Figure 3. Funnel plot of comparison: 1 Forest plot of comparison: primary outcomes, outcome: 1.1 Case fatality at the end of follow-up.

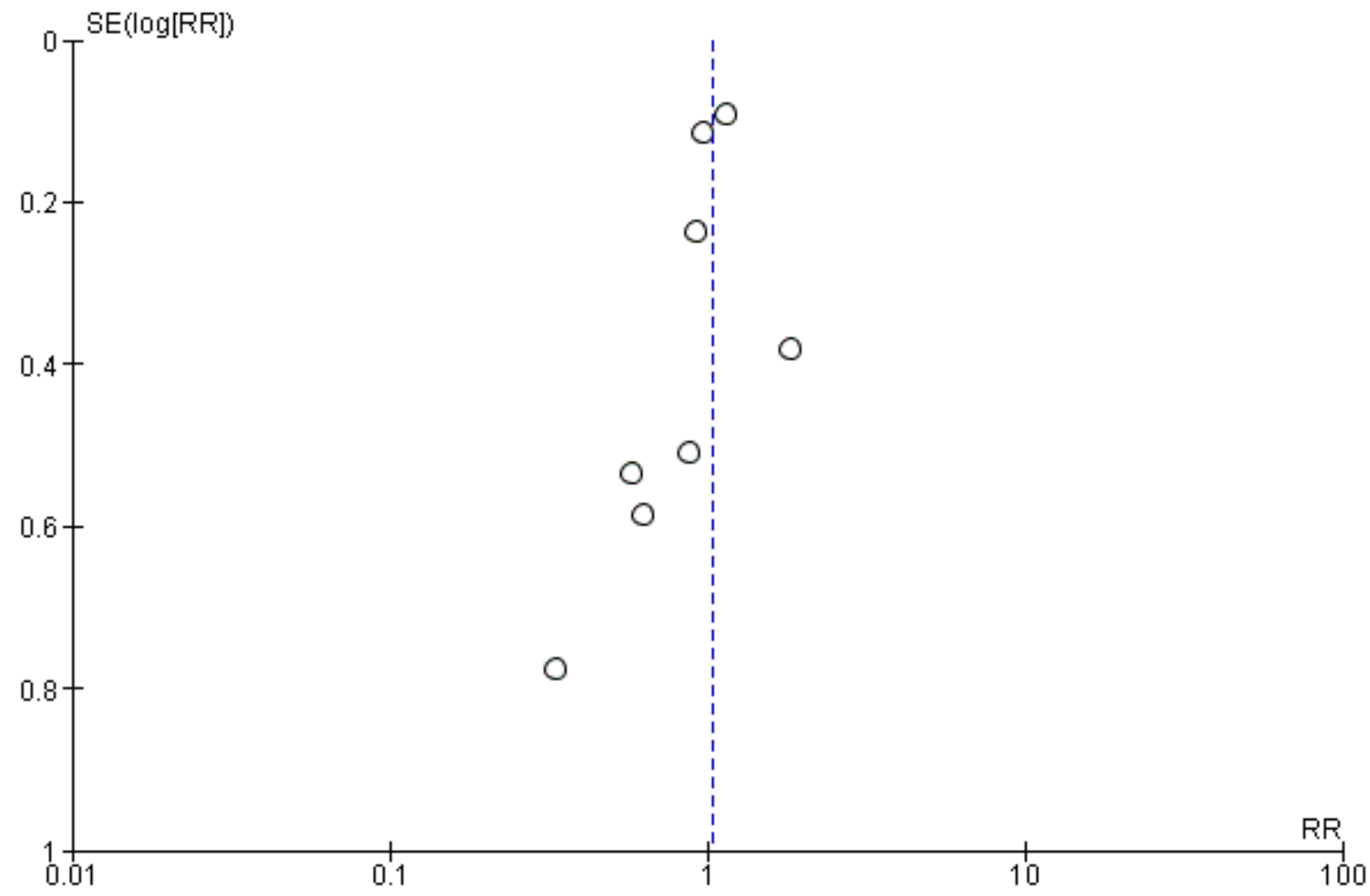


Figure 4. Funnel plot of comparison: 1 Forest plot of comparison: primary outcomes, outcome: 1.2 Death or dependency at the end of follow-up.

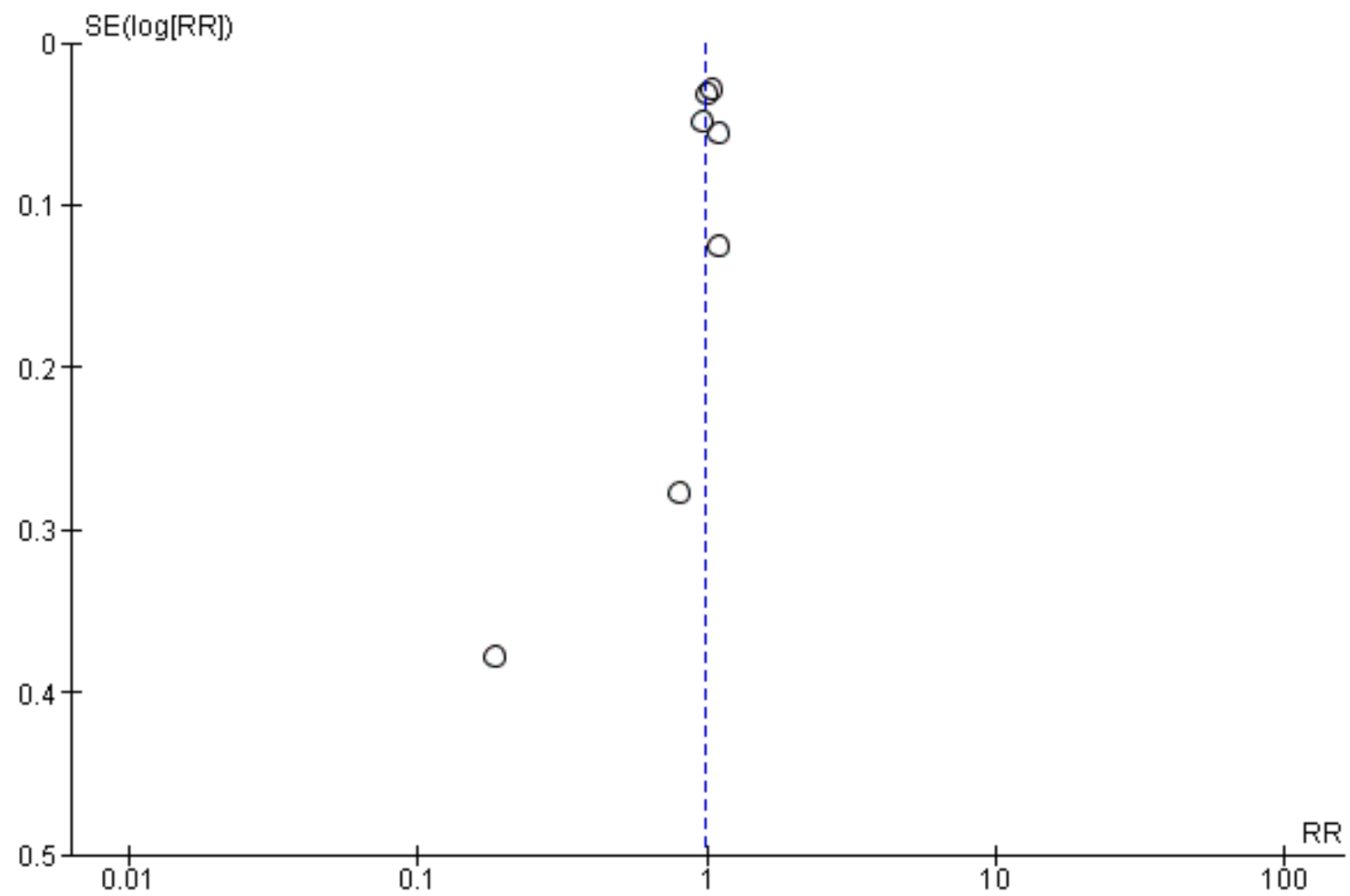

\section{Secondary outcomes}

The number of participants with any 'overall' infection at the end of follow-up was significantly reduced in the preventive antibiotics group: 408 of 2161 (19\%) compared with 558 of $2156(26 \%)$ in the control group (RR $0.71,95 \% \mathrm{Cl} 0.58$ to 0.88 ; high-quality evidence) (Analysis 2.1). Heterogeneity was substantial $\left(P=0.03 ; I^{2}=56 \%\right)$.

Regarding type of infection, urinary tract infections were highly significantly reduced: 81 of $2131(4 \%)$ participants in the preventive antibiotics group versus 204 of $2126(10 \%)$ in the control group (RR $0.40,95 \% \mathrm{Cl} 0.32$ to 0.51 ; high-quality evidence) (Analysis 2.2 ) (heterogeneity: $\mathrm{P}=0.70 ; \mathrm{I}^{2}=0 \%$ ), whereas no significant difference for pneumonia was found: 222 of $2131(10 \%)$ in the preventive antibiotics group versus 235 of $2126(11 \%)$ in the control group (RR $0.95,95 \% \mathrm{Cl} 0.80$ to 1.13 ; high-quality evidence) (Analysis 2.3 ) (heterogeneity: $\mathrm{P}=0.45 ; \mathrm{I}^{2}=0 \%$ ) (see funnel plots: Figure 5 , Figure 6 , and Figure 7). 
Figure 5. Funnel plot of comparison: 2 Forest plot of comparison: secondary outcomes, outcome: 2.1 Number of infections at the end of follow-up.

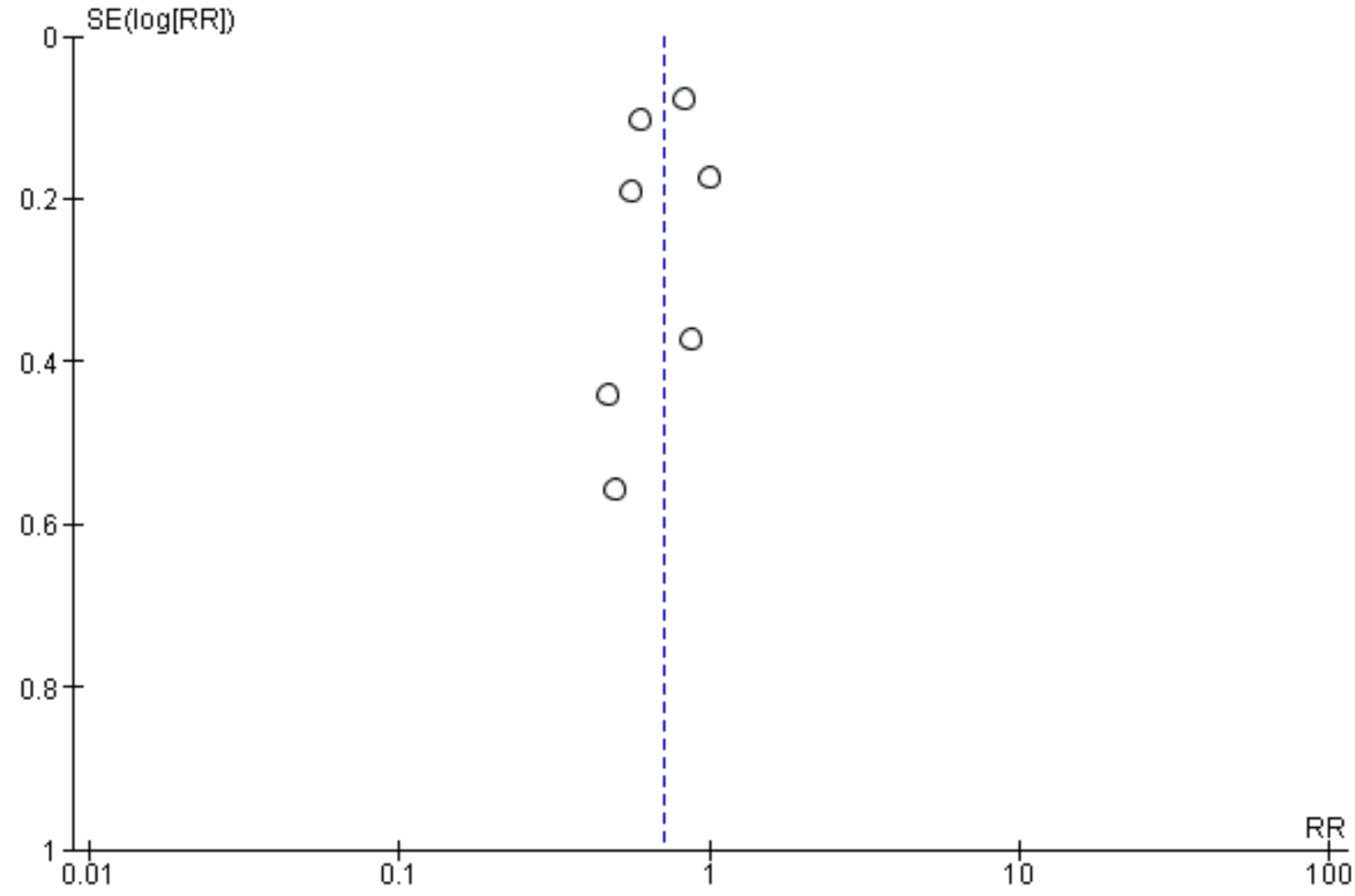


Figure 6. Funnel plot of comparison: 2 Forest plot of comparison: secondary outcomes, outcome: 2.2 Number of UTIs at the end of follow-up.

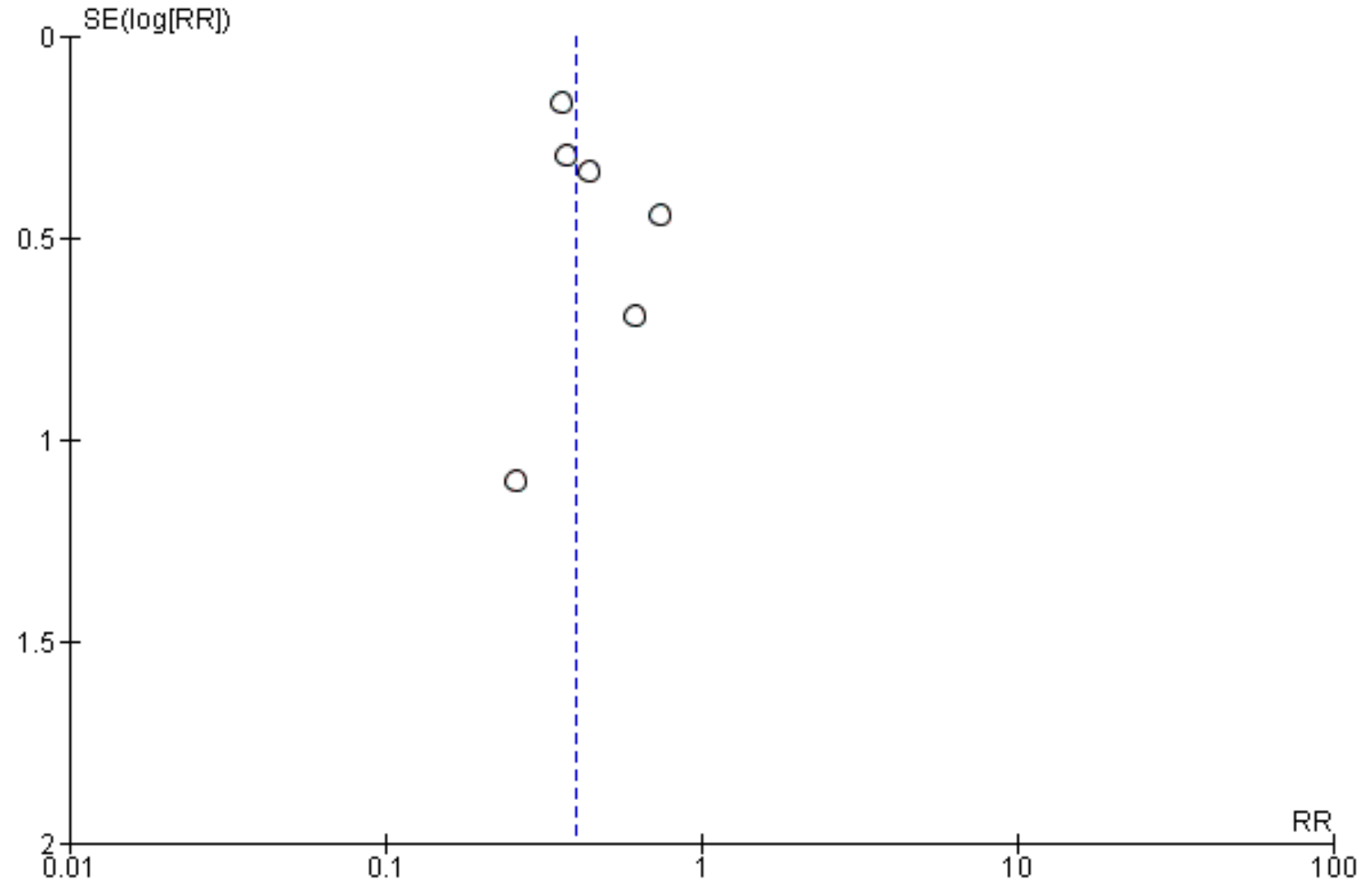


Figure 7. Funnel plot of comparison: 2 Forest plot of comparison: secondary outcomes, outcome: 2.3 Number of pneumonias at the end of follow-up.

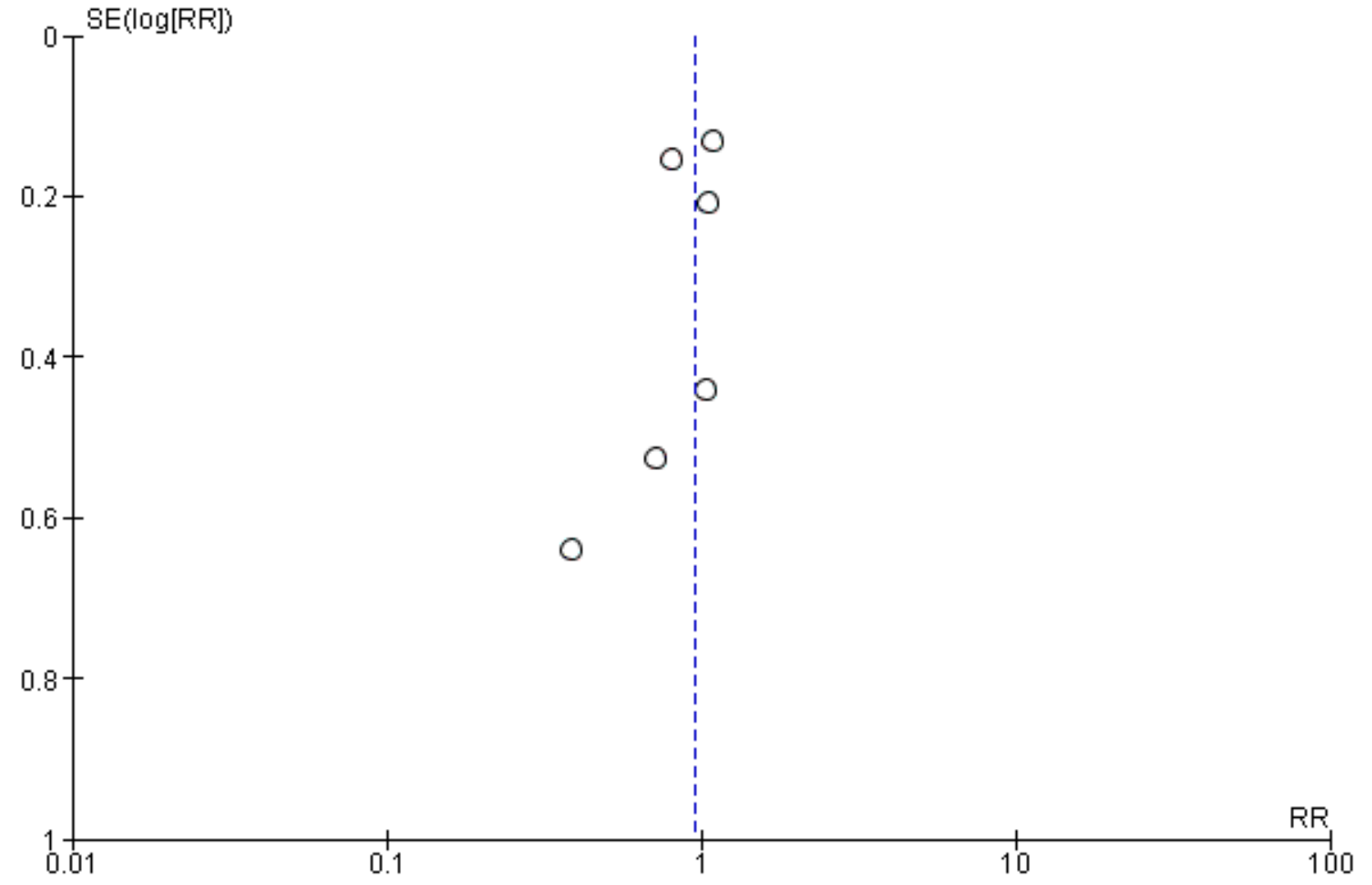

The occurrence of elevated body temperature was reported in two studies (Harms 2008; Schwarz 2008). Data were assessed qualitatively and could therefore not be pooled. Body temperature did not differ significantly between treatment groups according to one study, whereas temperatures were significantly higher in the conventional treatment group at days one, two, and three in the other study.

Only two studies reported data on length of hospital stay (Kalra 2015; Westendorp 2015). Data differed significantly, with a mean of six days in both treatment arms for Westendorp 2015 versus 24 days in the antibiotics group and 26 days in the control group for Kalra 2015.

Regarding adverse events, two studies reported none related to study medication (Harms 2008; Ulm 2016). In the other three studies reporting the occurrence of adverse events, the most frequently reported event was elevated liver or renal enzymes, or both (161 of 1887 participants; 9\%) (Kalra 2015; Schwarz 2008; Westendorp 2015). Clinical consequences were not reported for any of these participants. It has to be taken into account that a similar rate of adverse events was also reported in 136 of 1872 (7\%) of the control participants. Other reported adverse events included drug-induced exanthema in one participant (Schwarz 2008), 'allergic reaction causing cessation of ceftriaxone' in seven of 1242 participants (1\%) (Westendorp 2015), oliguria or raised plasma creatinine in 101 of 1242 participants (8\%) (compared with 112 of 1270 (9\%) in control participants) (Westendorp 2015), phlebitis in 15 of 1242 participants (1\%) (compared with nine of 1270 participants (1\%) in the control group) (Westendorp 2015), and infection by a ceftriaxone-resistant micro-organism in six of 1242 participants (1\%) (compared with five of 1270 (1\%) participants in the control group) (Westendorp 2015). The occurrence of colonisation with an antibiotic resistant microorganism was also reported in another study: one infection with methicillin-resistant Staphylococcus aureus (MRSA); however, colonisation was present before start of study medication (Harms 2008).

\section{Subgroup analyses}

Data were insufficient for predefined subgroup analyses regarding stroke severity and time of initiation of treatment. Two studies reported effects of stroke severity (Kalra 2015; Westendorp 2015); however, data do not overlap. Kalra 2015 assessed the relation between baseline NIHSS and risk of pneumonia and found no relationship. Westendorp 2015 also found no relationship between baseline NIHSS and functional outcomes. No study reported the time of the start of treatment.

Based on the finding that the number of participants with pneumonia was not significantly different for preventive antibiotics than for current best medical care, we performed a subanalysis of the studies in which any antibiotic could be used with the goal of preventing pneumonia (Kalra 2015; Ulm 2016). Again, we found no beneficial effect of preventive antibiotics: 131 of $727(18 \%)$ pneumonias in the antibiotics group versus 123 of $717(17 \%)$ in 
the control group (RR $1.08,95 \% \mathrm{Cl} 0,87$ to 1.34 ; moderate-quality evidence).

Also within this subgroup, we found no beneficial effect of preventive antibiotics on mortality: 209 out of 602 (35\%) in the antibiotics group versus 186 out of $686(28 \%)$ in the control group (RR $1.11 ; 95 \% \mathrm{Cl} 0.94$ to 1.32 ; moderate-quality evidence). This was also the case for poor functional outcome: 574 of 692 participants (83\%) in the preventive antibiotics group versus 548 of 686 participants (80\%) in the control group (RR 1.04; $95 \% \mathrm{Cl} 0.99$ to 1.10; moderate-quality evidence).

\section{Sensitivity analyses}

Two above-mentioned analyses showed significant heterogeneity, warranting stratification of the included studies for risk of bias. Using the Cochrane 'Risk of bias' tool, we considered two of the eight included studies to be at 'moderate' risk of bias (De Falco 1998; Lampl 2007); we considered the other six to be at 'low' risk of bias (Figure 1).

For the primary outcome 'death or dependency' $\left(I^{2}=79 \%\right)$, we excluded only Lampl 2007 from the initial analysis when stratifying studies with 'low risk of bias', because De Falco 1998 did not report functional outcomes on the mRS. When stratifying the six studies with 'low' risk of bias, again we noted no differences between both treatment arms: The number of participants with a poor functional outcome was 1151 of 2096 (55\%) in the preventive antibiotics group versus 1146 of 2095 (55\%) in the control group (RR 1.02, 95\% Cl 0.98 to 1.06 ; high-quality evidence) (heterogeneity: $P=0.39 ; I^{2}=4 \%$ ) (Analysis 3.1).

For the secondary outcome 'occurrence of overall infections' $\left(I^{2}=\right.$ $56 \%$ ), we excluded only De Falco 1998 from the initial calculation, because Lampl 2007 did not report the infection rate. Within the six studies with 'low' risk of bias, the numbers of participants with any 'overall' infection remained significantly lower: 404 of 2131 (19\%) in the preventive antibiotics group versus 550 of $2126(26 \%)$ in the control group (RR $0.72,95 \% \mathrm{Cl} 0.58$ to 0.89 ; high-quality evidence). Heterogeneity remained present as well $\left(P=0.02 ; 1^{2}=62 \%\right.$ ) (Analysis 3.2).

Regarding the predefined sensitivity analysis on study design, the primary outcome 'case fatality' remained unchanged: subanalysis of the two double-blinded randomised trials showed no significant effect on mortality, with a broad confidence interval: 22 of 106 (21\%) participants died in the preventive antibiotics group versus 14 of $109(13 \%)$ in the control group (RR $1.62,95 \% \mathrm{Cl} 0.87$ to 3.00; moderate-quality evidence), with substantial heterogeneity $\left(P=0.13 ; I^{2}=55 \%\right)$ (Analysis 3.3). Subanalysis of the openlabel trials showed a narrower confidence interval, again with no significant differences between treatment arms: 347 of 2064 (17\%) participants in the preventive antibiotics group died versus 337 of $2063(16 \%)$ in the control group (RR 1.03, 95\% Cl 0.90 to 1.17; highquality evidence), with no substantial heterogeneity $\left(P=0.26 ; I^{2}=\right.$ 24\%) (Analysis 3.4).

For the predefined sensitivity analysis on study design for the primary outcome 'functional outcome', we also found no significant differences in an analysis of the two double-blinded randomised trials: The number of participants with a poor functional outcome at the end of follow-up was 60 of $106(57 \%)$ in the preventive antibiotics group versus 61 of 109 (56\%) in the control group
(RR 1.02, 95\% Cl 0.78 to 1.35; moderate-quality evidence), with no substantial heterogeneity $\left(P=0.27 ; I^{2}=17 \%\right)$ (Analysis 3.5). In the subanalysis of the five open-label trials, 1198 of 2062 (58\%) participants in the preventive antibiotics group had a poor functional outcome versus 1121 of 2055 (55\%) in the control group (RR $0.98,95 \% \mathrm{Cl} 0.93$ to 1.03 ; high-quality evidence), with substantial heterogeneity $\left(P<0.0001 ; I^{2}=86 \%\right)$ (Analysis 3.6).

We have summarised the main results and have provided an explanation for determination of the quality of evidence in Summary of findings for the main comparison.

\section{DISCUSSION}

\section{Summary of main results}

This meta-analysis shows that preventive antibiotic therapy in people with ischaemic or haemorrhagic stroke did not reduce the risk of dependency and/or death. However, preventive antibiotic therapy did significantly reduce the occurrence of 'overall' infections from $26 \%$ to $19 \%$. Regarding type of infection, this was highly significant for urinary tract infections (4\% vs $10 \%$ ), whereas no effect on pneumonia was found ( $10 \%$ vs $11 \%)$. No major side effects of preventive antibiotic therapy were reported.

\section{Overall completeness and applicability of evidence}

The former version of this Cochrane review included a total of 506 participants from five studies with considerable heterogeneity in study population, study design, type of antibiotic, and definition of infection (Westendorp 2012). Owing to the large confidence intervals, it was not possible to draw conclusions on the effect of 'any' preventive antibiotic on mortality or stroke outcome (mortality: risk ratio (RR) $0.85,95 \%$ confidence interval (CI) 0.47 to 1.51; dependency: RR $0.67,95 \% \mathrm{Cl} 0.32$ to 1.43 ). Besides, study sizes were too small to specify the effect of preventive antibiotics on specific types of infection. It was concluded that the meta-analysis did not allow a very robust conclusion on the use of preventive antibiotic therapy in acute stroke.

With the completion of three large randomised controlled trials (RCTs) since 2012, the increase in study population to 4488 participants has now made it possible to evaluate the effect of preventive antibiotics on functional outcome and mortality. In general, the much larger study population has led to neutralisation of the former heterogeneity between studies. The current review shows that preventive antibiotic therapy did not reduce the risk of dependency or death or both in participants with acute stroke, whereas this therapy did significantly reduce the occurrence of 'overall' infections. The latter can now be specified, showing that this reduction is highly significant for urinary tract infections whereas no effect on pneumonia was found.

As was the case in the previous version of this meta-analysis, available studies have not adequately addressed several issues. Type of antibiotic therapy, dosage and duration varied between all eight studies, making it impossible to draw 'overall' conclusions regarding specific types of antibiotic regimens. Five studies used preventive antibiotic therapy that covered the common causative organisms in poststroke infections. Participants in two studies could use any antibiotic to prevent poststroke pneumonia. One study used minocycline to investigate a possible neuroprotective effect. This preventive antibiotic therapy did not effectively cover 
the antimicrobial spectrum of poststroke infections, and trial authors did not report infection rates (Lampl 2007).

Regarding the primary outcomes of this meta-analysis, only data on case fatality was reported in all studies. Dependency was reported as a mean score in one study (De Falco 1998), whereas the absolute number of dependent patients was necessary for a pooled analysis. This study showed a favourable effect of preventive antibiotic therapy on functional outcome on the Barthel Index (BI) and the Canadian Neurologic Scale (CNS). The pooled analysis does not include data from this study and was based on the seven studies that did report the number of dependent patients, along with mortality rates.

The number of infections was not reported in one study (Lampl 2007); therefore, we based the pooled estimate on seven studies. These seven studies used different definitions for the diagnosis of infection. Less strict definitions might lead to an overestimation of the number of infections, which could be a particular problem in studies with an open-label design. In a systematic meta-analysis on the incidence of poststroke infection, researchers found the overall pooled infection rate to be $30 \%$, and the rate of pneumonia and of urinary tract infection to be $10 \%$ (Westendorp 2011). These data appear to be in line with the observed overall infection rate in the current control group of $26 \%$, as well as the incidence of urinary tract infection (10\%) and of pneumonia (10\%).

No conclusions can be drawn on the effects of preventive antibiotic therapy on occurrence of elevated body temperature, length of hospital stay, and occurrence of opportunistic infections owing to lack of data. Limited data was also available on adverse events likely to be related to antibiotic therapy.

To account for heterogeneity in study design (double-blind vs openlabel studies), types of antibiotic therapy (adequately covering all pathogens in poststroke infections vs those mostly chosen for neuroprotective properties), and definitions of infection, we chose a random-effects model for the pooled analyses. In a fixed-effect model, it is assumed that differences between studies are due to chance, not to differences in study design. It is likely that results of this meta-analysis varied owing to the obvious heterogeneity between studies - not only owing to chance. We therefore preferred to use a random-effects model.

\section{Quality of the evidence}

Despite the fact that data have become more robust as compared with the previous version of this meta-analysis, and conclusions can now better be drawn, the decision of whether to use preventive antibiotic therapy in acute stroke should still be made with care owing to various factors. First, study design was heterogeneous, and, although this is better than in the previous version of this meta-analysis, the total of eight studies is limited. However, with a total of 4488 participants, it has now become possible to draw first 'overall' conclusions on the net effect of preventive antibiotic therapy in stroke. Second, as shown in the 'Risk of bias' table for each study, only four studies scored an overall 'low' risk of bias, and several biases may have influenced the results of included studies.

Selection bias could have confounded our results. Case fatality rates were low in all included studies, ranging from $9 \%$ to $29 \%$, with an average of $17 \%$. Usually, case fatality rates in acute stroke range from $15 \%$ to $25 \%$ (Van der Worp 2007). Three studies excluded people with a life expectancy of less than 90 days (Schwarz 2008; Ulm 2016; Westendorp 2015). Selection of less severely affected people may lead to an overestimation of the effects of preventive antibiotic therapy, because less effect could be expected in people with a high a priori case fatality risk. On the other hand, severely affected people might benefit the most from preventive antibiotic therapy. Stroke severity has previously been reported as a risk factor for poststroke infection, and the incidence of infection is higher amongst people with more severe stroke (Hamidon 2003; Kammersgaard 2001; Kwon 2006; Westendorp 2011).

According to blinding, six studies used an open-label design; in three of these studies, blinding of outcome parameters was incomplete or was not adequately described (De Falco 1998; Lampl 2007; Schwarz 2008). Knowledge of the intervention in a trial can affect the outcomes when provided care differs between treatment groups. Conduct of a study on preventive antibiotic therapy might have increased use of antibiotic therapy in the control group, which could lead to underestimation of a possible effect. Included studies did not specify prescription of antibiotic therapy in the control group; therefore these data could not be compared.

Detection bias might influence results when outcome is not assessed blindly. Two studies used a double-blind design in which all outcomes were assessed blindly (Chamorro 2005; Harms 2008). Three studies used an open-label design in which outcomes were assessed blindly by researchers masked to allocation (Kalra 2015; Ulm 2016; Westendorp 2015). In one study, infection was assessed blindly, but other outcomes were not (Schwarz 2008); and two studies did not assess outcomes blindly or did not describe outcome assessment (De Falco 1998; Lampl 2007). Despite the open-label design and/or the incomplete/unclear method of blinding in six of the eight included studies, it is unlikely that one of the primary endpoints in current meta-analysis (case fatality) was influenced because this is a hard endpoint. Less objective endpoints, such as score on the modified Rankin Scale (mRS), could have been influenced, but this effect might be overcome by blinding of the endpoint. The most vulnerable outcome measurement, however, is infection rate. Because treating physicians were probably aware of participation in a study on (preventive) antibiotics, (over)alertness about the occurrence of infection in study participants is likely. With an open-label design, this might even be more applicable to the group not given preventive antibiotic treatment. On the other hand, infections might be less easily diagnosed in participants allocated to the experimental group, who are receiving preventive antibiotics. (Over)alertness to infection in the control group, as compared with possible underdiagnosis of infection in the experimental group, might lead to overestimation of a possible effect.

At least the overdiagnosis of infections in the control group was not found in current meta-analysis. The overall incidence of any infection in the acute phase after stroke is approximately $30 \%$ (Westendorp 2011); in current meta-analysis, infections occurred in $19 \%$ in the preventive antibiotic group versus $26 \%$ in the control group in studies with an open-label design; in comparison with $16 \%$ in the preventive antibiotic group versus $24 \%$ in the placebo group in studies with a double-blind design.

A recent review described considerable variation in terminology and in the diagnostic approach to pneumonia (Kishore 2015). Recently, consensus operational criteria for the terminology and 
diagnosis of stroke-associated pneumonia have been proposed based on criteria of the Centers for Disease Control and Prevention (CDC) (Smith 2015). For future studies, standardised definitions such as those provided by the CDC are preferable, especially in open-label trials. Four of eight studies applied criteria derived from the CDC, mainly as secondary analyses (Chamorro 2005; Kalra 2015; Ulm 2016; Westendorp 2015). The incidence of infection based on these criteria appears to be relatively lower.

Attrition bias can occur when trial participants are withdrawn after randomisation. For example, side effects of medication (nausea, diarrhoea, exanthema, etc) might lead to exclusion of participants owing to their inability to complete the course, introducing bias in favour of one study arm. In this current meta-analysis, only one study reported no loss to follow-up at all (Schwarz 2008). In seven of the eight included studies, attrition bias might have occurred. Kalra 2015 reported no loss to follow-up for the primary endpoint (assessed after 14 days), but did describe loss to followup for the secondary endpoints (assessed after 90 days). Chamorro 2005 also reported all participants in the primary analysis but did not provide counts of participants for secondary outcomes; loss to follow-up might have occurred. Westendorp 2015 described in detail the numbers of participants lost to follow-up; these were equally distributed over both study groups. Harms 2008 (seven participants) and Ulm 2016 (30 participants) reported numbers of participants lost to follow-up, without mentioning further details. De Falco 1998 and Lampl 2007 did not report at all the numbers of participants lost to follow-up.

\section{Potential biases in the review process}

Using multiple overlapping searches of various databases, we aimed to include all relevant publications in this review. However we cannot totally exclude the possibility that small randomised clinical trials, published in journals with a lower impact factor, might have been missed. We aimed to minimise this risk by developing a new search strategy with the help of the Cochrane Stroke Group's Information Specialist, instead of using the strategy of the former version of this meta-analysis, as well as completely reperforming the selection of studies, instead of only updating the selection from the date of the former search.

Another strategy that we used to minimise the risk of missing small studies was to search trials registries and prepare funnel plots (Figure 3; Figure 4; Figure 5; Figure 6; Figure 7). In the trial registries, we identified only one study that was still ongoing. The funnel plots do show heterogeneity, but they have improved in comparison with the previous version of this meta-analysis. Furthermore, a high prevalence of incomplete outcome reporting exists (Smyth 2011), which also could have affected our metaanalysis: in only three of the eight included studies were incomplete outcome data adequately addressed. By contacting trial authors to request additional information for inclusion in our prespecified analyses, we tried to minimise this influence.

\section{Agreements and disagreements with other studies or reviews}

The previous version of this Cochrane review - Westendorp 2012 was an update of a systematic review and meta-analysis performed in 2009 (Van de Beek 2009). Results of previous meta-analyses are consistent with the findings of current version.

\section{AUTHORS' CONCLUSIONS}

\section{Implications for practice}

Currently, use of preventive antibiotic therapy is not included in standard care for people with acute stroke (Jauch 2013). Results of this meta-analysis do not provide evidence that current practice should be changed. Despite the large number of participants, the included studies were heterogeneous, and further research is warranted to translate current conclusions of 'overall' preventive antibiotics to specific antibiotic regimens and/or stroke subtypes.

\section{Implications for research}

Compared with the previous version of this meta-analysis, the more robust results in the current analyses, leading to smaller confidence intervals and the shift of effect sizes on functional outcomes and mortality towards no effect, have now made it possible to draw first conclusions on the effects of 'overall' preventive antibiotics in stroke. However, studies remain heterogeneous and it is not possible to draw conclusions on specific types of antibiotics. Besides, it could be suggested that people with different subtypes of stroke do benefit from preventive antibiotics, as was noted for thrombolysed patients in a recent post hoc analysis (Vermeij 2016). A pooled analysis of current large trials is being planned to further evaluate effects of preventive antibiotics on this, and other, potential subgroups.

In addition to research on the potential beneficial effects of preventive antibiotics, an interesting finding in the current metaanalysis is the fact that the incidence of 'overall' infections and urinary tract infections can be significantly reduced, whereas pneumonia - which of all infections is clearly most often associated with poor outcome (Westendorp 2011) - cannot be prevented. Additional studies on this finding are necessary, since this might explain the absence of beneficial effects of preventive antibiotics on dependency and mortality. A possible explanation for the observed effect is that pneumonia is not simply a bacterial infection, but may result from (poststroke) chemical and immunological alterations resulting in a 'pneumonitis' in which the role of cultured bacteria is very limited. In case of this pneumonitis prevention by antibiotics is impossible.

\section{ACKNOWLEDGEMENTS}

This work is supported by grants from the Netherlands Organization for Health Research and Development (ZonMW; 171002302) and the Netherlands Heart Foundation (Hartstichting; 2009B095). We especially thank Prof A Meisel for permitting us to use unpublished data from the STRAWINSKI trial in favour of this meta-analysis. We also thank Dr A Chamorro, Dr M Boaz, and Dr $Y$ Lampl, for providing additional data from their studies. Finally, we thank B van de Veen (BvdV) for assessing risk of bias of the manuscript by Westendorp et al. 
REFE RE N CES

\section{References to studies included in this review}

Chamorro 2005 \{published data only\}

Chamorro A, Horcajada JP, Obach V, Vargas M, Revilla M, Torres F, et al. The Early Systemic Prophylaxis of Infection After Stroke study: a randomized clinical trial. Stroke 2005;36(7):1495-500.

\section{De Falco 1998 \{published data only\}}

De Falco FA, Santangelo R, Majello L, Angelone P. Antimicrobial prophylaxis in the management of ischemic stroke. Rivista di Neurobiologia 1998;44(1):63-7.

\section{Harms 2008 \{published data only\}}

Harms H, Prass K, Meisel C, Klehmet J, Rogge W, Drenckhahn C, et al. Preventive antibacterial therapy in acute ischemic stroke: a randomized controlled trial. PLOS ONE 2008;3(5):e2158.

\section{Kalra 2015 \{published data only\}}

Kalra L, Irshad S, Hodsoll J, Simpson M, Gulliford M, Smithard D, STROKE-INF Investigators. Prophylactic antibiotics after acute stroke for reducing pneumonia in patients with dysphagia (STROKE-INF): a prospective, cluster-randomised, openlabel, masked endpoint, controlled clinical trial. Lancet 2015;386(10006):1835-44.

\section{Lampl 2007 \{published data only\}}

Lampl Y, Boaz M, Gilad R, Lorberboym M, Dabby R, Rapoport A, et al. Minocycline treatment in acute stroke: an open-label, evaluator-blinded study. Neurology 2007;69(14):1404-10.

\section{Schwarz 2008 \{published data only\}}

Schwarz S, Al-Shajlawi F, Sick C, Meairs S, Hennerici MG. Effects of prophylactic antibiotic therapy with mezlocillin plus sulbactam on the incidence and height of fever after severe acute ischemic stroke: the Mannheim Infection in Stroke Study (MISS). Stroke 2008;39(4):1220-7.

\section{Ulm 2016 \{unpublished data only\}}

Meisel A. The randomised controlled STRAWINSKI trial: procalcitonin-guided antibiotic therapy after stroke (preliminary title). Unpublished.

\section{Westendorp 2015 \{published data only\}}

Westendorp WF, Vermeij JD, Zock E, Hooijenga IJ, Kruyt ND, Bosboom HJ, PASS Investigators. The Preventive Antibiotics in Stroke Study (PASS): a pragmatic randomised open-label masked endpoint clinical trial. Lancet 2015;385(9977):1519-26.

\section{References to ongoing studies}

\section{ISRCTN82217627 \{unpublished data only\}}

ISRCTN82217627. Prevention of complications to Improve outcome in elderly patients with acute stroke - a randomised clinical trial. www.isrctn.com/ISRCTN82217627 (first received 29 August 2015)

\section{Additional references}

\section{Carnaby 2006}

Carnaby G, Hankey GJ, Pizzi J. Behavioural intervention for dysphagia in acute stroke: a randomised controlled trial. Lancet Neurology 2006;5(1):31-7.

\section{Chamorro 2006}

Chamorro A, Amaro S, Vargas M, Obach V, Cervera A, Torres F, et al. Interleukin 10, monocytes and increased risk of early infection in ischaemic stroke. Journal of Neurology, Neurosurgery and Psychiatry 2006;77(11):1279-81.

\section{Emsley 2008}

Emsley HC, Hopkins SJ. Acute ischaemic stroke and infection: recent and emerging concepts. Lancet Neurology 2008; $7(4): 341-53$

\section{Finlayson 2011}

Finlayson O, Kapral M, Hall R, Asllani E, Selchen D, Saposnik G, Canadian Stroke Network, Stroke Outcome Research Canada (SORCan) Working Group. Risk factors, inpatient care, and outcomes of pneumonia after ischemic stroke. Neurology 2011;77:1338-45.

\section{Haeusler 2008}

Haeusler KG, Schmidt WU, Fohring F, Meisel C, Helms T, Jungehulsing GJ, et al. Cellular immunodepression preceding infectious complications after acute ischemic stroke in humans. Cerebrovascular Diseases 2008;25(1-2):50-8.

\section{Hamidon 2003}

Hamidon BB, Raymond AA. Risk factors and complications of acute ischaemic stroke patients at Hospital Universiti Kebangsaan Malaysia (HUKM). Medical Journal of Malaysia 2003;58(4):499-505.

\section{Higgins 2016}

Higgins JPT, Lasserson T, Chandler J, Tovey D, Churchill R. Methodological Expectations of Cochrane Intervention Reviews. London: Cochrane, 2016.

\section{Jauch 2013}

Jauch EC, Saver JL, Adams HP, Bruno A, Connors JJ, Demaerschalk BM, American Heart Association Stroke Council, Council on Cardiovascular Nursing, Council on Peripheral Vascular Disease, and Council on Clinical Cardiology. Guidelines for the early management of patients with acute ischemic stroke: a guideline for healthcare professionals from the American Heart Association/American Stroke Association. Stroke 2013;44:870-947.

\section{Kammersgaard 2001}

Kammersgaard LP, Jorgensen HS, Reith J, Nakayama H, Houth JG, Weber UJ, et al. Early infection and prognosis after acute stroke: the Copenhagen Stroke Study. Journal of Stroke and Cerebrovascular Diseases 2001;10(5):217-21. 


\section{Kishore 2015}

Kishore AK, Vail A, Chamorro A, Garau J, Hopkins SJ, Di Napoli M, et al. How is pneumonia diagnosed in clinical stroke research? A systematic review and meta-analysis. Stroke 2015;46:1202-9.

\section{Kwon 2006}

Kwon HM, Jeong SW, Lee SH, Yoon BW. The pneumonia score: a simple grading scale for prediction of pneumonia after acute stroke. American Journal of Infection Control 2006;34(2):64-8.

\section{Lee 2007}

Lee M, Huang WY, Weng HH, Lee JD, Lee TH. First-ever ischemic stroke in very old Asians: clinical features, stroke subtypes, risk factors and outcome. European Neurology 2007;58(1):44-8.

\section{Martino 2005}

Martino R, Foley N, Bhogal S, Diamant N, Speechley M, Teasell R. Dysphagia after stroke: incidence, diagnosis, and pulmonary complications. Stroke 2005;36(12):2756-63.

\section{Popović 2013}

Popović N, Stefanović-Budimkić M, Mitrović N, Urošević A, Milošević $\mathrm{B}$, Pelemiš $\mathrm{M}$, et al. The frequency of poststroke infections and their impact on early stroke outcome. Journal of Stroke and Cerebrovascular Diseases 2013;22:424-9.

\section{RevMan 2014 [Computer program]}

The Nordic Cochrane Centre, The Cochrane Collaboration. Review Manager (RevMan). Version 5.3. Copenhagen: The Nordic Cochrane Centre, The Cochrane Collaboration, 2014.

\section{Smith 2015}

Smith CJ, Kishore AK, Vail A, Chamorro A, Garau J, Hopkins SJ, et al. Diagnosis of stroke-associated pneumonia: recommendations from the Pneumonia in Stroke Consensus Group. Stroke 2015;46(8):2335-40.

\section{Smyth 2011}

Smyth RM, Kirkham JJ, Jacoby A, Altman DG, Gamble C, Williamson PR. Frequency and reasons for outcome reporting bias in clinical trials: interviews with trialists. BMJ 2011;342:c7153.

\section{Stott 2009}

Stott DJ, Falconer A, Miller H, Tilston JC, Langhorne P. Urinary tract infection after stroke. QJM 2009;102(4):243-9.

\section{Van de Beek 2009}

Van de Beek D, Wijdicks EF, Vermeij FH, De Haan RJ, Prins JM, Spanjaard $\mathrm{L}$, et al. Preventive antibiotics for infections in acute stroke: a systematic review and meta-analysis. Archives of Neurology 2009;66(9):1076-81.

\section{Van der Worp 2007}

Van der Worp HB, Van Gijn J. Clinical practice. Acute ischemic stroke. New England Journal of Medicine 2007;357(6):572-9.

\section{Vargas 2006}

Vargas M, Horcajada JP, Obach V, Revilla M, Cervera A, Torres F, et al. Clinical consequences of infection in patients with acute stroke: is it prime time for further antibiotic trials?. Stroke 2006;37(2):461-5.

\section{Vermeij 2009}

Vermeij FH, Scholte op Reimer WJ, De Man P, Van Oostenbrugge RJ, Franke CL, De Jong G, et al. Strokeassociated infection is an independent risk factor for poor outcome after acute ischemic stroke: data from the Netherlands Stroke Survey. Cerebrovascular Diseases 2009;27(5):465-71.

\section{Vermeij 2016}

Vermeij JD, Westendorp WF, Roos YB, Brouwer MC, van de Beek D, Nederkoorn PJ, PASS Investigators. Preventive ceftriaxone in patients with stroke treated with intravenous thrombolysis: post hoc analysis of the Preventive Antibiotics in Stroke Study. Cerebrovascular Diseases 2016;42(5-6):361-9.

\section{Walter 2007}

Walter U, Knoblich R, Steinhagen V, Donat M, Benecke R, Kloth A. Predictors of pneumonia in acute stroke patients admitted to a neurological intensive care unit. Journal of Neurology 2007;254(10):1323-9.

\section{Westendorp 2011}

Westendorp WF, Nederkoorn PJ, Vermeij JD, Dijkgraaf MG, van de Beek D. Post-stroke infection: a systematic review and metaanalysis. BMC Neurology 2011;20;11:100.

\section{Yilmaz 2007}

Yilmaz GR, Cevik MA, Erdinc FS, Ucler S, Tulek N. The risk factors for infections acquired by cerebral hemorrhage and cerebral infarct patients in a neurology intensive care unit in Turkey. Japanese Journal of Infectious Diseases 2007;60(2-3):87-91.

\section{References to other published versions of this review Vermeij 2010}

Vermeij F, Nederkoorn PJ, Den Hertog HM, Van de Beek D, Dippel DWJ. Antibiotic therapy for preventing infections in patients with acute stroke. Cochrane Database of Systematic Reviews 2010, Issue 6. [DOI: 10.1002/14651858.CD008530]

\section{Westendorp 2012}

Westendorp WF, Vermeij JD, Vermeij F, Den Hertog HM, Dippel DW, van de Beek D, et al. Antibiotic therapy for preventing infections in patients with acute stroke. Cochrane Database of Systematic Reviews 2012, Issue 1. [DOI: 10.1002/14651858.CD008530.pub2]

\section{CHARACTERISTICS OF STUDIES}

Characteristics of included studies [ordered by study ID] 
Chamorro 2005

\begin{tabular}{|c|c|c|}
\hline Methods & \multicolumn{2}{|c|}{ Randomised, double-blind } \\
\hline Participants & \multicolumn{2}{|c|}{$\begin{array}{l}\text { People older than } 18 \text { years with non-septic ischaemic or haemorrhagic stroke enrolled within } 24 \text { hours } \\
\text { from clinical onset }\end{array}$} \\
\hline Interventions & \multicolumn{2}{|c|}{ Intravenous levofloxacin $500 \mathrm{mg} / 100 \mathrm{~mL} / \mathrm{d}$, for 3 days } \\
\hline Outcomes & \multicolumn{2}{|c|}{$\begin{array}{l}\text { Early infection (within the first } 7 \text { days after stroke), case fatality, favourable outcome at day } 90 \text { (mRS }< \\
2, \text { NIHSS }<2, \mathrm{BI} 95 \text { or } 100 \text { ) }\end{array}$} \\
\hline Notes & \multicolumn{2}{|l|}{-} \\
\hline \multicolumn{3}{|l|}{ Risk of bias } \\
\hline Bias & Authors' judgement & Support for judgement \\
\hline $\begin{array}{l}\text { Random sequence genera- } \\
\text { tion (selection bias) }\end{array}$ & Low risk & Participants were randomised via a computer-generated number sheet \\
\hline $\begin{array}{l}\text { Allocation concealment } \\
\text { (selection bias) }\end{array}$ & Low risk & $\begin{array}{l}\text { Participants were randomly allocated to } 1 \text { of the } 2 \text { treatment groups; a phar- } \\
\text { macist, nurse, or fellow opened a numbered sealed envelope. Study treatment } \\
\text { was prepared at the central pharmacy of the institution and was kept within its } \\
\text { premises until allocation. }\end{array}$ \\
\hline $\begin{array}{l}\text { Blinding (performance } \\
\text { bias and detection bias) } \\
\text { All outcomes }\end{array}$ & Low risk & $\begin{array}{l}\text { Double-blind design, placebo controlled. Outcome assessment (e.g. occur- } \\
\text { rence of infections) was assessed blindly because physicians were not aware of } \\
\text { treatment allocation. }\end{array}$ \\
\hline $\begin{array}{l}\text { Incomplete outcome data } \\
\text { (attrition bias) } \\
\text { All outcomes }\end{array}$ & Low risk & $\begin{array}{l}\text { Table } 2 \text { indicates that all participants were seen at } 90 \text { days. Counts of partici- } \\
\text { pants with secondary outcomes by treatment were not provided. }\end{array}$ \\
\hline $\begin{array}{l}\text { Selective reporting (re- } \\
\text { porting bias) }\end{array}$ & Low risk & $\begin{array}{l}\text { All outcomes were reported (infections, case fatality, unfavourable functional } \\
\text { outcome). }\end{array}$ \\
\hline Other bias & Low risk & No other sources of bias were found. \\
\hline
\end{tabular}

De Falco 1998

\begin{tabular}{ll}
\hline Methods & Randomised, unblinded \\
\hline Participants & People with ischaemic stroke within 12 hours from clinical onset \\
\hline Interventions & Penicillin intramuscularly \\
\hline Outcomes & Infectious complications, case fatality, functional outcome $(\mathrm{BI}, \mathrm{CNS})$ \\
\hline Notes & -
\end{tabular}

\section{Risk of bias}

\begin{tabular}{lll}
\hline Bias & Authors' judgement & Support for judgement \\
\hline $\begin{array}{l}\text { Random sequence genera- } \\
\text { tion (selection bias) }\end{array}$ & Unclear risk & The study was described as 'randomized'. \\
\hline
\end{tabular}


De Falco 1998 (Continued)

Allocation concealment $\quad$ Unclear risk $\quad$ Allocation concealment was not mentioned.
(selection bias)

Blinding (performance High risk

bias and detection bias)

All outcomes
This study appears to have an open-label design; blinding of outcome assessment was not described.

\begin{tabular}{lll}
$\begin{array}{l}\text { Incomplete outcome data } \\
\text { (attrition bias) } \\
\text { All outcomes }\end{array}$ & High risk & $\begin{array}{l}\text { Nothing was reported about completeness of follow-up and outcome assess- } \\
\text { ment. }\end{array}$ \\
\hline $\begin{array}{l}\text { Selective reporting (re- } \\
\text { porting bias) }\end{array}$ & High risk & $\begin{array}{l}\text { Outcome assessment was performed at discharge instead of at a fixed time } \\
\text { point. }\end{array}$
\end{tabular}
porting bias)

Other bias Low risk No other sources of bias were found.

Harms 2008

\begin{tabular}{ll}
\hline Methods & Randomised, double-blind \\
\hline Participants & $\begin{array}{l}\text { People older than } 17 \text { years with ischaemic stroke in MCA territory and NIHSS } \geq 12 \text { within } 9 \text { to } 36 \text { hours } \\
\text { after onset }\end{array}$ \\
\hline Interventions & Intravenous moxifloxacin $400 \mathrm{mg} / \mathrm{d}$ for 5 days \\
\hline Outcomes & $\begin{array}{l}\text { Infection rate within } 11 \text { days after stroke onset, bacterial spectrum, moxifloxacin resistance, daily max- } \\
\text { imum body temperature, CRP, survival and functional outcome }(\mathrm{BI}) \text { at day } 180 \text { after stroke }(\mathrm{BI} \text { was di- } \\
\text { chotomised } \geq 60 \text { and }<60)\end{array}$ \\
\hline Notes & - \\
\hline
\end{tabular}

\section{Risk of bias}

\begin{tabular}{|c|c|c|}
\hline Bias & Authors' judgement & Support for judgement \\
\hline $\begin{array}{l}\text { Random sequence genera- } \\
\text { tion (selection bias) }\end{array}$ & Low risk & A computer-generated allocation schedule was used. \\
\hline $\begin{array}{l}\text { Allocation concealment } \\
\text { (selection bias) }\end{array}$ & Low risk & $\begin{array}{l}\text { Trial pharmacists at each site labelled trial drugs with sequential study num- } \\
\text { bers according to randomisation lists prepared by the trial statistician and dis- } \\
\text { pensed drugs. }\end{array}$ \\
\hline $\begin{array}{l}\text { Blinding (performance } \\
\text { bias and detection bias) } \\
\text { All outcomes }\end{array}$ & Low risk & Study investigators and enrolling staff were masked to assignments. \\
\hline $\begin{array}{l}\text { Incomplete outcome data } \\
\text { (attrition bias) } \\
\text { All outcomes }\end{array}$ & High risk & 7 participants were lost to follow-up; no details were mentioned. \\
\hline $\begin{array}{l}\text { Selective reporting (re- } \\
\text { porting bias) }\end{array}$ & Low risk & $\begin{array}{l}\text { All outcomes (infection, neurological outcome, adverse events, and case fatali- } \\
\text { ty) were reported at prespecified intervals. }\end{array}$ \\
\hline Other bias & Low risk & No other sources of bias were found. \\
\hline
\end{tabular}


Kalra 2015

\begin{tabular}{ll}
\hline Methods & Cluster-randomised, open-label, blinded endpoint \\
\hline Participants & $\begin{array}{l}\text { People aged older than } 18 \text { years, confirmed diagnosis of new stroke (ischaemic or haemorrhagic), on- } \\
\text { set of symptoms within } 48 \text { hours at recruitment, unsafe to swallow because of impaired consciousness, } \\
\text { failed bedside swallow test, or presence of a nasogastric tube }\end{array}$ \\
\hline
\end{tabular}

Interventions Antibiotic choice conformed to local antibiotic policy by dose and by route according to local guidelines. Amoxicillin or co-amoxiclav, together with clarithromycin for 7 days, was recommended if no restrictions were applied.

Outcomes Poststroke pneumonia was determined by a statistician masked to allocation using a criteria-based hierarchical algorithm; pneumonia was diagnosed by the local treating physician.

NIHSS at 14 days; death at 14 and 90 days; functional outcome at 90 days on mRS; CDT-positive diarrhoea; MRSA colonisation; EuroQoL at 90 days; physician-diagnosed pneumonia at baseline and at 2, 7 , 10 , and 14 days; length of hospital stay; time to death

Notes

\section{Risk of bias}

\begin{tabular}{|c|c|c|}
\hline Bias & Authors' judgement & Support for judgement \\
\hline $\begin{array}{l}\text { Random sequence genera- } \\
\text { tion (selection bias) }\end{array}$ & Low risk & $\begin{array}{l}\text { Minimisation algorithm, stratifying centres for number of stroke admissions } \\
\text { per year and proportion admitted directly to specialist care. Randomisation } \\
\text { was computer generated and was done away from the trial office. }\end{array}$ \\
\hline $\begin{array}{l}\text { Allocation concealment } \\
\text { (selection bias) }\end{array}$ & Low risk & $\begin{array}{l}\text { Participants, research staff obtaining data, and statisticians undertaking } \\
\text { analyses of outcome data were unaware of stroke unit allocation. Randomisa- } \\
\text { tion was computer generated and was done away from the trial office. }\end{array}$ \\
\hline $\begin{array}{l}\text { Blinding (performance } \\
\text { bias and detection bias) } \\
\text { All outcomes }\end{array}$ & Low risk & $\begin{array}{l}\text { Participants, research staff obtaining data, and statisticians undertaking } \\
\text { analyses of outcome data were unaware of stroke unit allocation. Detec- } \\
\text { tion bias for the primary outcome between groups was minimised by a cri- } \\
\text { teria-based algorithm for diagnosis of poststroke pneumonia, applied blind } \\
\text { to the whole dataset. Outcomes at } 90 \text { days were assessed by trial office re- } \\
\text { searchers masked to allocation. }\end{array}$ \\
\hline
\end{tabular}

$\begin{array}{ll}\begin{array}{l}\text { Incomplete outcome data Low risk } \\ \text { (attrition bias) }\end{array} & \begin{array}{l}\text { No participants were lost to follow-up at the primary endpoint; } 2 \text { participants } \\ \text { in the antibiotic group withdrew consent, and } 16 \text { ( } 3 \%) \text { in the control group } \\ \text { All outcomes }\end{array} \\ \begin{array}{l}\text { and } 18(3 \%) \text { in the antibiotic group could not be contacted for the } 90-\text { day fol- } \\ \text { low-up. }\end{array}\end{array}$

$\begin{array}{ll}\begin{array}{l}\text { Selective reporting (re- } \\ \text { porting bias) }\end{array} & \text { Low risk } \\ & \begin{array}{l}\text { come, mortality, CDT-positive diarrhoea, MRSA colonisation, EuroQoL scores, } \\ \text { hospital stay) were reported at prespecified intervals. }\end{array}\end{array}$

Other bias Low risk No other sources of bias were found.

Methods Quasi-randomised (8th number of identity card), open-label, blinded outcome assessment


Lampl 2007 (Continued)

Participants People older than 18 years with ischaemic stroke, NIHSS $>5$, and onset of stroke 6 to 24 hours before start of treatment

\begin{tabular}{ll}
\hline Interventions & Orally minocycline $200 \mathrm{mg} / \mathrm{d}$ for 5 days \\
\hline Outcomes & NIHSS on day $90 ;$ NIHSS, $\mathrm{mRS}, \mathrm{BI}$, and death on days 7,30 , and 90 \\
\hline
\end{tabular}

Notes -

\section{Risk of bias}

Bias Authors' judgement Support for judgement

Random sequence genera- High risk The 8th number on the participant's identity card was used. tion (selection bias)

Allocation concealment High risk After contacting the trial author by email, we received an email from the epi(selection bias) demiologist of this trial. Allocation concealment was described as follows.

"A patient arrived at the emergency room with signs of stroke. Emergency room personnel were aware that the study was recruiting participants and identified patients who met study inclusion criteria. Once this identification was made, the attending physician in the emergency room phoned me regardless of the time, day or night. In the emergency room were sealed, numbered packages containing medication. The attending physician read me the eighth digit of the patient's National Identity number. I referred to a randomization list which had been computer-generated prior to study onset, and based on whether the eighth digit was odd or even, the randomization list assigned the patient to a numbered package. The attending physician then provided the medication inside the appropriately numbered package to the patient. Thus, the attending physician in the emergency room was blind to the treatment assignment. I was not blind to the treatment assignment, however, and was aware of the patient's treatment assignment. I, therefore, consider this trial open label".

In conclusion, we do not know for sure whether blinding was maintained on the ward of the hospital. It is possible that physicians were aware of the treatment because they knew that participants with even/odd NID numbers would get a certain treatment.

\begin{tabular}{|c|c|c|}
\hline $\begin{array}{l}\text { Blinding (performance } \\
\text { bias and detection bias) }\end{array}$ & Low risk & $\begin{array}{l}\text { Blinded study; outcomes were assessed blindly (although the adequacy of } \\
\text { blind was not described) }\end{array}$ \\
\hline
\end{tabular}
All outcomes

\begin{tabular}{|c|c|c|}
\hline $\begin{array}{l}\text { Incomplete outcome data } \\
\text { (attrition bias) }\end{array}$ & High risk & $\begin{array}{l}\text { The number of participants lost to follow-up was not reported. Scores on } \\
\text { NIHSS, BI, and mRS were presented as means. }\end{array}$ \\
\hline
\end{tabular}

Alloutcomes

Selective reporting (re- Low risk $\quad$ All outcomes were reported.
porting bias)

porting bias)

Other bias Low risk No other sources of bias were found.

Methods Randomised, unblinded


Schwarz 2008 (Continued)

Participants

People aged at least 18 years with ischaemic stroke and onset of symptoms less than 24 hours ago, bedridden $(\mathrm{mRS}>3$ ), with estimated premorbid $\mathrm{mRS}<2$ and stable deficits

\begin{tabular}{ll}
\hline Interventions & Intravenous mezlocillin $2 \mathrm{~g}$ and sulbactam $1 \mathrm{~g}$ every 8 hours for 4 days (12 infusions in total) \\
\hline Outcomes & mRS at day 90, infection, daily temperature \\
\hline Notes & $\begin{array}{l}\text { Infection was assessed by blinded observer; primary outcome (mRS at day } 90) \text { was assessed by tele- } \\
\text { phone interview with unknown blinding procedure. }\end{array}$
\end{tabular}

\section{Risk of bias}

\begin{tabular}{|c|c|c|}
\hline Bias & Authors' judgement & Support for judgement \\
\hline $\begin{array}{l}\text { Random sequence genera- } \\
\text { tion (selection bias) }\end{array}$ & Low risk & $\begin{array}{l}\text { Randomisation was performed via a computer-generated number sheet and a } \\
\text { numbered, sealed envelope. }\end{array}$ \\
\hline $\begin{array}{l}\text { Allocation concealment } \\
\text { (selection bias) }\end{array}$ & Low risk & $\begin{array}{l}\text { Randomisation was performed via a computer-generated number sheet and a } \\
\text { numbered, sealed envelope. }\end{array}$ \\
\hline $\begin{array}{l}\text { Blinding (performance } \\
\text { bias and detection bias) } \\
\text { All outcomes }\end{array}$ & High risk & $\begin{array}{l}\text { This was an open-label design. Assessment of infections during the study pe- } \\
\text { riod was done by a blinded observer, but assessment of secondary outcomes, } \\
\text { such as NIHSS and mRS, was not done in a blinded fashion. }\end{array}$ \\
\hline $\begin{array}{l}\text { Incomplete outcome data } \\
\text { (attrition bias) } \\
\text { All outcomes }\end{array}$ & Low risk & Data show no losses to follow-up. \\
\hline $\begin{array}{l}\text { Selective reporting (re- } \\
\text { porting bias) }\end{array}$ & Low risk & Data show no losses to follow-up in this study, not even at 90 days. \\
\hline Other bias & Low risk & No other sources of bias were found. \\
\hline
\end{tabular}

UIm 2016

\begin{tabular}{ll}
\hline Methods & Randomised, open-label with blinded outcome assessment \\
\hline Participants & $\begin{array}{l}\text { People aged } 18 \text { years or older, with severe ischaemic stroke (score }>9 \text { on the NIHSS) and clinical diag- } \\
\text { nosis of a stroke in the MCA territory }\end{array}$ \\
\hline Interventions & $\begin{array}{l}\text { Standard stroke care plus daily ultrasensitive procalcitonin (PCTus)-guided antibiotic treatment. If PC- } \\
\text { Tus concentration was higher than } 0.05 \text { ng/mL, a bacterial infection was considered likely and use of } \\
\text { antibiotics was recommended. Type and duration of antibiotic treatment - focusing on stroke-associat- } \\
\text { ed pneumonia - were left to the treating physician. }\end{array}$ \\
\hline Outcomes & mRS at 7 days and 3 months, death at 7 and 30 days, infection rate, total antibiotic use, BI at 3 months \\
\hline Notes & -
\end{tabular}

\section{Risk of bias}

\begin{tabular}{lll}
\hline Bias & Authors' judgement & Support for judgement \\
\hline $\begin{array}{l}\text { Random sequence genera- } \\
\text { tion (selection bias) }\end{array}$ & Low risk & Use of random number generator \\
\hline \hline
\end{tabular}


Ulm 2016 (Continued)

Allocation concealment Low risk Numbered sealed, opaque envelopes
(selection bias)

\begin{tabular}{|c|c|c|}
\hline $\begin{array}{l}\text { Blinding (performance } \\
\text { bias and detection bias) } \\
\text { All outcomes }\end{array}$ & Low risk & $\begin{array}{l}\text { This was an open-label study. Outcome assessment of mRS at } 3 \text { months was } \\
\text { adequately blinded: centrally assessed by structured telephone interviews } \\
\text { conducted by trained staff members masked to allocation }\end{array}$ \\
\hline
\end{tabular}

\begin{tabular}{ll}
\hline $\begin{array}{l}\text { Incomplete outcome data } \\
\text { (attrition bias) }\end{array}$ & Low risk \\
All outcomes & $\begin{array}{l}\text { Primary outcome was centrally assessed by structured telephone interviews } \\
\text { conducted by staff members at the study centre. All secondary outcomes were } \\
\text { reported, except for length of stay and use of antibiotics, owing to method- } \\
\text { ological restrictions. }\end{array}$
\end{tabular}

\begin{tabular}{lll}
\hline $\begin{array}{l}\text { Selective reporting (re- } \\
\text { porting bias) }\end{array}$ & Low risk & $\begin{array}{l}\text { Figure 2 showing patient flow through the study was missing from the manu- } \\
\text { script; cannot be sure if all participants were accounted for at follow-up }\end{array}$ \\
\hline Other bias & Low risk & No other sources of bias were found. \\
\hline
\end{tabular}

Westendorp 2015

\begin{tabular}{ll}
\hline Methods & Randomised, open-label, blinded endpoint \\
\hline Participants & $\begin{array}{l}\text { People aged } 18 \text { years or older with clinical symptoms of stroke (ischaemic or haemorrhagic), onset of } \\
\text { symptoms within less than } 24 \text { hours, score } \geq 1 \text { on the NIHSS }\end{array}$ \\
\hline Interventions & Intravenous ceftriaxone $2 \mathrm{~g} / \mathrm{d}$ for 4 days \\
\hline Outcomes & $\begin{array}{l}\text { mRS at } 3 \text { months, death at discharge and } 3 \text { months after randomisation, infection rate, total antimicro- } \\
\text { bial use, length of hospital stay, volume of poststroke care, and quality-adjusted life-years and costs }\end{array}$ \\
\hline Notes & -
\end{tabular}

\section{Risk of bias}

\begin{tabular}{lll}
\hline Bias & Authors' judgement & Support for judgement \\
\hline $\begin{array}{l}\text { Random sequence genera- } \\
\text { tion (selection bias) }\end{array}$ & Low risk & $\begin{array}{l}\text { Online tool, stratified according to study centre (university hospital, large non- } \\
\text { university hospital, or small non-university hospital) and stroke severity (score } \\
\text { on NIHSS of } 1 \text { to } 9 \text { vs score } \geq 10 \text { ), with permuted blocks of varying block size } \\
\text { (with maximum block size of } 6)\end{array}$ \\
\hline $\begin{array}{l}\text { Allocation concealment } \\
\text { (selection bias) }\end{array}$ & Low risk & $\begin{array}{l}\text { Online tool within 24 hours after symptom onset. Local investigators and par- } \\
\text { ticipants were not masked, but research nurses who did the follow-up inter- } \\
\text { views were masked to treatment allocation. }\end{array}$ \\
\hline $\begin{array}{l}\text { Blinding (performance } \\
\text { bias and detection bias) } \\
\text { All outcomes }\end{array}$ & Low risk & $\begin{array}{l}\text { Local investigators and participants were not masked, but research nurs- } \\
\text { es who did the follow-up interviews were masked to treatment allocation. }\end{array}$ \\
& $\begin{array}{l}\text { Trained and masked research nurses based at the Academic Medical Center } \\
\text { assessed functional outcomes at 3 months using a validated structured tele- } \\
\text { phone interview. }\end{array}$ \\
\hline $\begin{array}{l}\text { Incomplete outcome data } \\
\text { (attrition bias) } \\
\text { All outcomes }\end{array}$ & Low risk & $\begin{array}{l}\text { 24 participants were lost to follow-up (11 in the ceftriaxone group and 13 in the } \\
\text { control group); details are mentioned in the appendix of the manuscript. }\end{array}$ \\
\hline
\end{tabular}


Westendorp 2015 (Continued)

Selective reporting (re- Low risk $\quad$ All outcomes were reported.
porting bias)

Other bias Low risk No other sources of bias were found.

BI: Barthel Index.

CDT: Clostridium difficile toxin.

CNS: Canadian Neurologic Scale.

CRP: C-reactive protein.

EuroQoL: measure of health-related quality of life.

MCA: middle cerebral artery.

mRS: modified Rankin Scale.

MRSA: methicillin-resistant Staphylococcus aureus.

NID: National Identity number.

NIHSS: National Institutes of Health Stroke Scale.

Characteristics of ongoing studies [ordered by study ID]

ISRCTN82217627

Trial name or title

PRECIOUS: PREvention of Complications to Improve OUtcome in elderly patients with acute Stroke. A randomized, open, phase III, clinical trial with blinded outcome assessment

Methods

International, multi-centre, multi-factorial, randomised controlled, open-label trial with blinded outcome assessment

Participants

Adults over 66 years of age with a clinical diagnosis of acute ischaemic stroke or intracerebral haemorrhage

Inclusion criteria:

- Clinical diagnosis of acute ischaemic stroke or intracerebral haemorrhage (confirmed on CT or MRI scan)

- Score on NIHSS $\geq 6$, indicating moderately severe to severe stroke

- Aged 66 years or older

- Possibility to start trial treatment within 12 hours of symptom onset

Exclusion criteria:

All participants:

- Active infection requiring antibiotic treatment, as judged by the treating physician

- Pre-stroke score on the $\mathrm{mRS} \geq 4$

- Death appearing imminent at the time of assessment

For the ceftriaxone arm:

- Known hypersensitivity to beta-lactam antibiotics

For the paracetamol arm:

- Known hypersensitivity to paracetamol or any of the excipients

- Known severe hepatic insufficiency

- Chronic alcoholism

For the metoclopramide arm:

- Hypersensitivity to metoclopramide or to any of the excipients 
- Gastrointestinal haemorrhage, mechanical obstruction, or gastro-intestinal perforation, for which stimulation of gastrointestinal motility constitutes a risk

- Confirmed or suspected pheochromocytoma

- History of neuroleptic or metoclopramide-induced tardive dyskinesia

- Epilepsy

- Parkinson's disease

- Use of levodopa or dopaminergic agonists

- Known history of methaemoglobinaemia with metoclopramide, or of NADH cytochrome-b5 deficiency

Interventions

Participants will be randomly allocated in a $2^{\star} 2^{\star} 2$ factorial design to any combination of open-label oral or rectal metoclopramide (10 mg 3 times daily); intravenous ceftriaxone (2000 mg once daily); or oral, rectal, or intravenous paracetamol ( $1000 \mathrm{mg} 4$ times daily); or to usual care, started within 12 hours after symptom onset and continued for 4 days or until complete recovery or discharge from hospital, if earlier. Allocation will be based on proportional minimisation through a web-based allocation service. Investigators will have the opportunity to censor a single specific randomisation arm in a specific participant before randomisation, for example in case of an allergy to 1 of the interventions. Participants will have follow-up at 7 and 91 days.

Outcomes Primary outcome: handicap as assessed by score on the mRS at 91 days $( \pm 14)$, and analysed via ordinal logistical regression

Secondary outcomes:

At 7 days ( \pm 1 day) or at discharge, if earlier:

- Infection in the first 7 days ( \pm 1 day; frequency, type, and Clostridium difficile infection). Infections will be categorised as diagnosed by the clinician, and as judged by an independent adjudication committee (masked to treatment allocation)

- Third-generation cephalosporin resistance in the first 7 days ( \pm 1 day), detected as part of routine clinical practice

- Antimicrobial use during the first 7 days ( \pm 1 day), converted to units of defined daily doses according to the classification of the WHO Anatomical Therapeutic Chemical Classification System with Defined Daily Doses Index

- In a subgroup of patients, presence of extended-spectrum beta-lactamase (ESBL)-producing bacteria as detected by PCR in a rectal swab

At 91 days ( \pm 14 days):

- Death

- Unfavourable functional outcome, defined as mRS 3 to 6

- Disability assessed by score on the BI

- Cognition assessed by MoCA

- Quality of life assessed by EuroQol 5D-5L (EQ-5D-5L)

- Home time: duration of stay in the patient's own home or in a relative's home over the first 90 days

- Participant location over first 91 days ( \pm 14 days): hospital; rehabilitation service; long-term care nursing facility; home

- SAEs in the first 14 days

\begin{tabular}{ll}
\hline Starting date & June 2015 \\
\hline Contact information & $\begin{array}{l}\text { Dr Bart van der Worp, Department of Neurology and Neurosurgery, Brain Center Rudolf Magnus, } \\
\text { University Medical Center Utrecht, The Netherlands }\end{array}$ \\
\hline
\end{tabular}

Notes

BI: Barthel Index. 
$\mathrm{CT}$ : computerised tomography.

EQ-5D-5L: EuroQoL Group quality of life questionnaire based on a five-level scale.

ESBL: extended-spectrum beta-lactamase.

MoCA: Montreal Cognitive Assessment.

MRI: magnetic resonance imaging.

mRS: modified Rankin Scale.

NIHSS: National Institutes of Health Stroke Scale.

PCR: polymerase chain reaction.

SAE: serious adverse event.

WHO: World Health Organization.

\section{DATA AND ANALYSES}

Comparison 1. Forest plot of comparison: primary outcomes

\begin{tabular}{lllll}
\hline Outcome or subgroup title & No. of studies & $\begin{array}{l}\text { No. of partici- } \\
\text { pants }\end{array}$ & Statistical method & Effect size \\
\hline 1 Case fatality at the end of follow-up & 8 & 4422 & $\begin{array}{l}\text { Risk Ratio (M-H, Random, } \\
95 \% \text { Cl) }\end{array}$ & $1.03[0.87,1.21]$ \\
\hline $\begin{array}{l}\text { 2 Death or dependency at the end of fol- } \\
\text { low-up }\end{array}$ & 7 & 4332 & $\begin{array}{l}\text { Risk Ratio (M-H, Random, } \\
95 \% \text { Cl) }\end{array}$ & $0.99[0.89,1.10]$ \\
\hline
\end{tabular}

\section{Analysis 1.1. Comparison 1 Forest plot of comparison: primary outcomes, Outcome 1 Case fatality at the end of follow-up.}

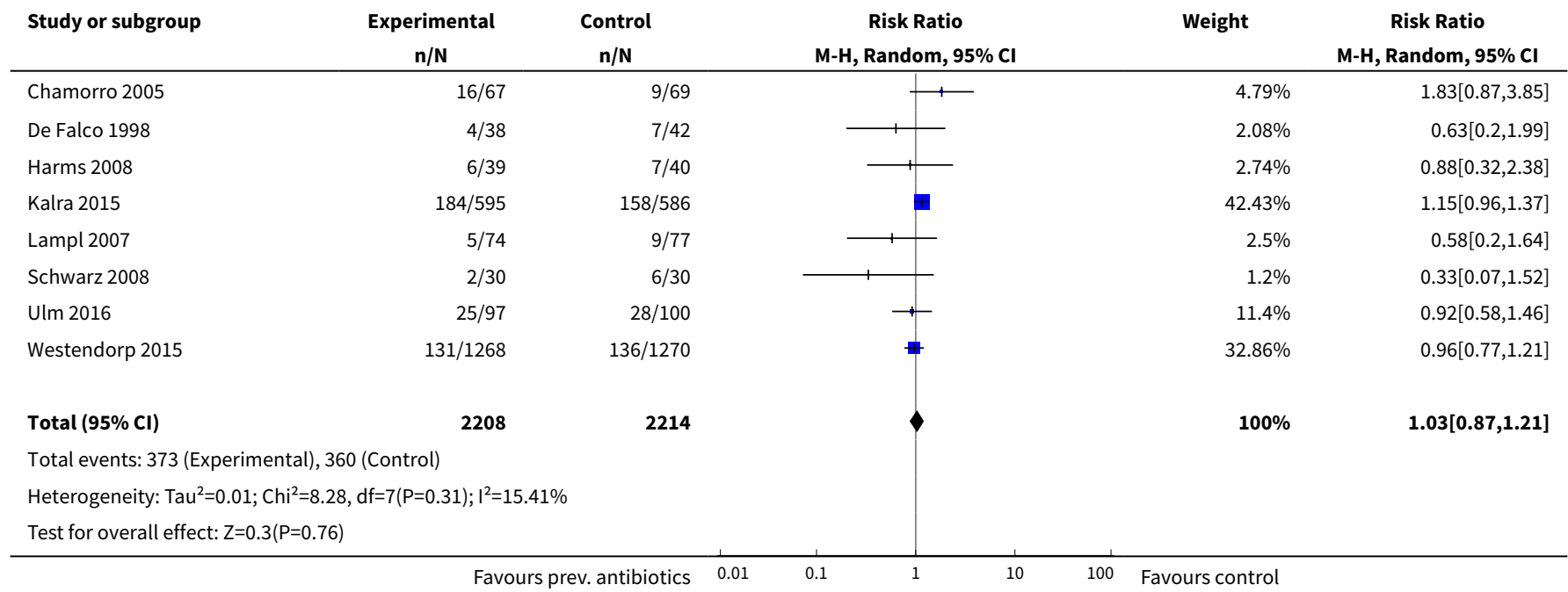


Analysis 1.2. Comparison 1 Forest plot of comparison: primary outcomes, Outcome 2 Death or dependency at the end of follow-up.

\begin{tabular}{|c|c|c|c|c|c|}
\hline Study or subgroup & $\begin{array}{c}\text { Experimental } \\
\mathrm{n} / \mathrm{N}\end{array}$ & $\begin{array}{c}\text { Control } \\
n / N\end{array}$ & $\begin{array}{c}\text { Risk Ratio } \\
\text { M-H, Random, } 95 \% \mathrm{Cl}\end{array}$ & Weight & $\begin{array}{c}\text { Risk Ratio } \\
\text { M-H, Random, } 95 \% \mathrm{CI}\end{array}$ \\
\hline Chamorro 2005 & $46 / 67$ & $43 / 69$ & + & $10.17 \%$ & $1.1[0.86,1.41]$ \\
\hline Harms 2008 & $14 / 39$ & $18 / 40$ & 十 & $3.09 \%$ & $0.8[0.46,1.37]$ \\
\hline Kalra 2015 & $486 / 595$ & $465 / 586$ & $\phi$ & $23 \%$ & $1.03[0.97,1.09]$ \\
\hline Lampl 2007 & $7 / 72$ & $36 / 69$ & 1 & $1.76 \%$ & $0.19[0.09,0.39]$ \\
\hline Schwarz 2008 & $30 / 30$ & $30 / 30$ & 申 & $22.54 \%$ & $1[0.94,1.07]$ \\
\hline Ulm 2016 & $88 / 97$ & $83 / 100$ & * & $19.25 \%$ & $1.09[0.98,1.22]$ \\
\hline Westendorp 2015 & $487 / 1268$ & $507 / 1270$ & - & $20.19 \%$ & $0.96[0.87,1.06]$ \\
\hline Total $(95 \% \mathrm{CI})$ & 2168 & 2164 & 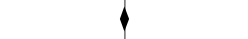 & $100 \%$ & $0.99[0.89,1.1]$ \\
\hline \multicolumn{6}{|c|}{ Total events: 1158 (Experimental), 1182 (Control) } \\
\hline \multicolumn{6}{|c|}{ Heterogeneity: Tau $^{2}=0.01 ; \mathrm{Chi}^{2}=28.72, \mathrm{df}=6(\mathrm{P}<0.0001) ; \mathrm{I}^{2}=79.11 \%$} \\
\hline Test for overall effec & & & & & \\
\hline
\end{tabular}

\section{Comparison 2. Forest plot of comparison: secondary outcomes}

\begin{tabular}{lllll}
\hline Outcome or subgroup title & No. of studies & $\begin{array}{l}\text { No. of partici- } \\
\text { pants }\end{array}$ & Statistical method & Effect size \\
\hline $\begin{array}{l}1 \text { Number of infections at the end of fol- } \\
\text { low-up }\end{array}$ & 7 & 4317 & $\begin{array}{l}\text { Risk Ratio (M-H, Random, } \\
95 \% \mathrm{Cl})\end{array}$ & $0.71[0.58,0.88]$ \\
\hline 2 Number of UTIs at the end of follow-up & 6 & 4257 & $\begin{array}{l}\text { Risk Ratio (M-H, Random, } \\
95 \% \mathrm{Cl})\end{array}$ & $0.40[0.32,0.51]$ \\
\hline $\begin{array}{l}\text { 3 Number of pneumonias at the end of } \\
\text { follow-up }\end{array}$ & 6 & 4257 & $\begin{array}{l}\text { Risk Ratio (M-H, Random, } \\
95 \% \mathrm{Cl})\end{array}$ & $0.95[0.80,1.13]$ \\
\hline
\end{tabular}

Analysis 2.1. Comparison 2 Forest plot of comparison: secondary outcomes, Outcome 1 Number of infections at the end of follow-up.

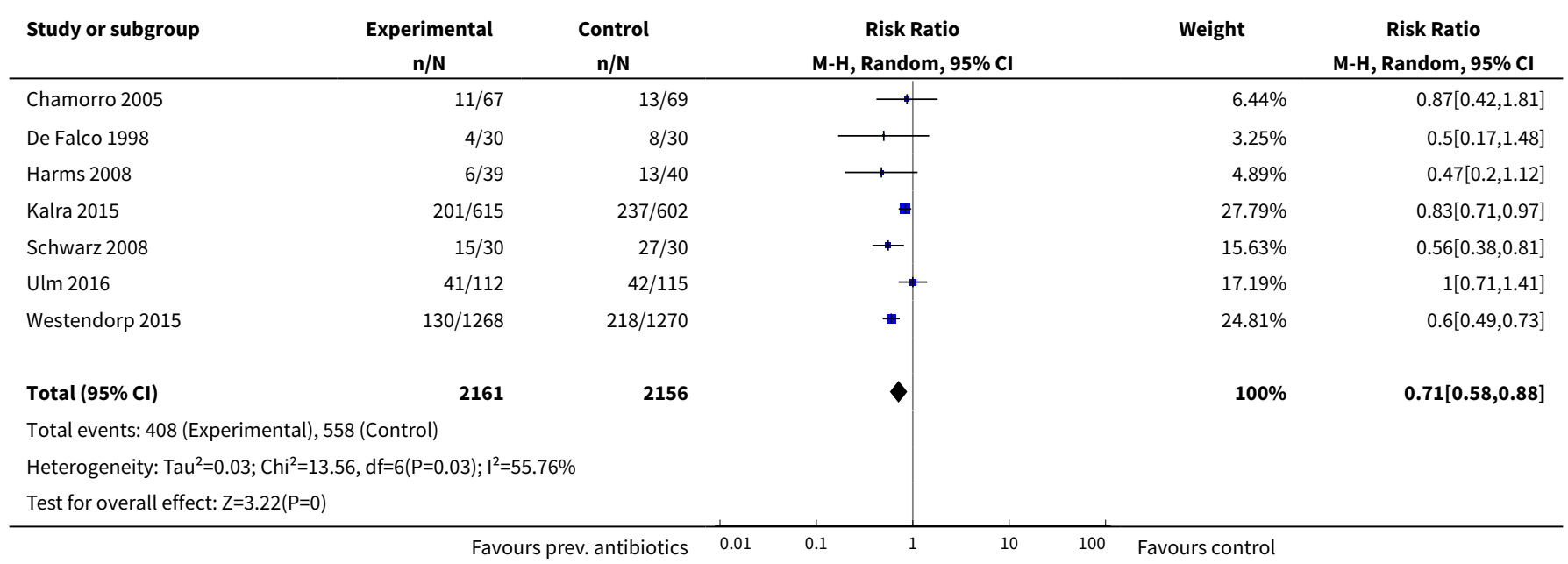


Analysis 2.2. Comparison 2 Forest plot of comparison: secondary outcomes, Outcome 2 Number of UTIs at the end of follow-up.

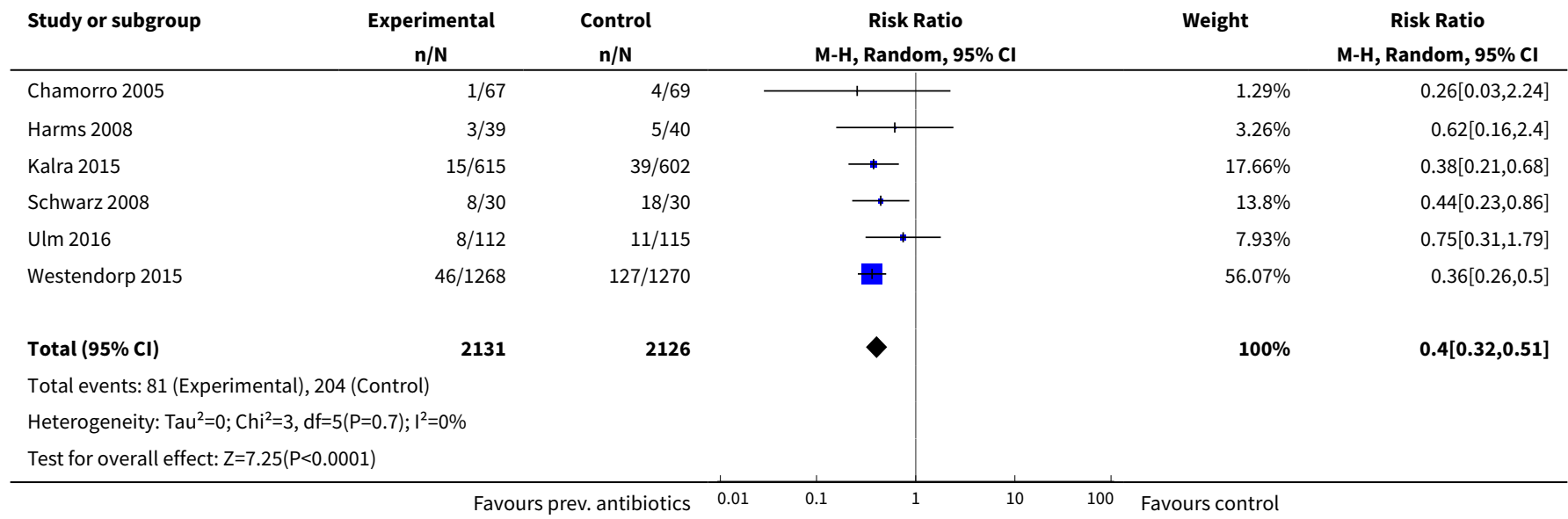

Analysis 2.3. Comparison 2 Forest plot of comparison: secondary outcomes, Outcome 3 Number of pneumonias at the end of follow-up.

\begin{tabular}{|c|c|c|c|c|c|}
\hline Study or subgroup & $\begin{array}{c}\text { Experimental } \\
n / N\end{array}$ & $\begin{array}{c}\text { Control } \\
n / N\end{array}$ & $\begin{array}{c}\text { Risk Ratio } \\
\text { M-H, Random, 95\% Cl }\end{array}$ & Weight & $\begin{array}{c}\text { Risk Ratio } \\
\text { M-H, Random, 95\% Cl }\end{array}$ \\
\hline Chamorro 2005 & $9 / 67$ & $9 / 69$ & 1 & $3.91 \%$ & $1.03[0.44,2.44]$ \\
\hline Harms 2008 & $3 / 39$ & $8 / 40$ & + & $1.85 \%$ & $0.38[0.11,1.34]$ \\
\hline Kalra 2015 & $101 / 615$ & $91 / 602$ & 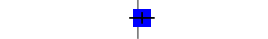 & $42.8 \%$ & $1.09[0.84,1.41]$ \\
\hline Schwarz 2008 & $5 / 30$ & $7 / 30$ & \begin{tabular}{l|l} 
\\
1
\end{tabular} & $2.73 \%$ & $0.71[0.25,2]$ \\
\hline Ulm 2016 & $33 / 112$ & $32 / 115$ & $\rightarrow$ & $17.15 \%$ & $1.06[0.7,1.6]$ \\
\hline Total $(95 \% \mathrm{Cl})$ & 2131 & 2126 & $>$ & $100 \%$ & $0.95[0.8,1.13]$ \\
\hline \multicolumn{6}{|c|}{ Total events: 222 (Experimental), 235 (Control) } \\
\hline \multicolumn{6}{|c|}{ Heterogeneity: $\mathrm{Tau}^{2}=0 ; \mathrm{Chi}^{2}=4.74, \mathrm{df}=5(\mathrm{P}=0.45) ; \mathrm{I}^{2}=0 \%$} \\
\hline Test for overall effect & & & & & \\
\hline
\end{tabular}

Comparison 3. Forest plot of comparison: sensitivity analyses

\begin{tabular}{lllll}
\hline Outcome or subgroup title & No. of studies & $\begin{array}{l}\text { No. of partici- } \\
\text { pants }\end{array}$ & Statistical method & Effect size \\
\hline $\begin{array}{l}\text { 1 Functional outcome: low risk of bias } \\
\text { studies }\end{array}$ & 6 & 4191 & $\begin{array}{l}\text { Risk Ratio (M-H, Random, } \\
95 \% \mathrm{Cl})\end{array}$ & $1.02[0.98,1.06]$ \\
\hline $\begin{array}{l}2 \text { Number of infections: low risk of } \\
\text { bias studies }\end{array}$ & 6 & 4257 & $\begin{array}{l}\text { Risk Ratio (M-H, Random, } \\
95 \% \mathrm{Cl})\end{array}$ & $0.72[0.58,0.89]$ \\
\hline $\begin{array}{l}\text { 3 Case fatality: double-blind design } \\
\text { n }\end{array}$ & 2 & 215 & $\begin{array}{l}\text { Risk Ratio (M-H, Fixed, 95\% } \\
\mathrm{Cl})\end{array}$ & $1.62[0.87,3.00]$ \\
\hline
\end{tabular}




\begin{tabular}{|c|c|c|c|c|}
\hline Outcome or subgroup title & No. of studies & $\begin{array}{l}\text { No. of partici- } \\
\text { pants }\end{array}$ & Statistical method & Effect size \\
\hline 4 Case fatality: open-label design & 5 & 4127 & $\begin{array}{l}\text { Risk Ratio (M-H, Fixed, 95\% } \\
\mathrm{Cl})\end{array}$ & $1.03[0.90,1.17]$ \\
\hline $\begin{array}{l}5 \text { Functional outcome: double-blind } \\
\text { design }\end{array}$ & 2 & 215 & $\begin{array}{l}\text { Risk Ratio (M-H, Fixed, 95\% } \\
\mathrm{Cl})\end{array}$ & $1.01[0.80,1.27]$ \\
\hline $\begin{array}{l}6 \text { Functional outcome: open-label de- } \\
\text { sign }\end{array}$ & 5 & 4117 & $\begin{array}{l}\text { Risk Ratio (M-H, Fixed, 95\% } \\
\mathrm{Cl} \text { ) }\end{array}$ & $0.98[0.93,1.03]$ \\
\hline
\end{tabular}

Analysis 3.1. Comparison 3 Forest plot of comparison: sensitivity analyses, Outcome 1 Functional outcome: low risk of bias studies.

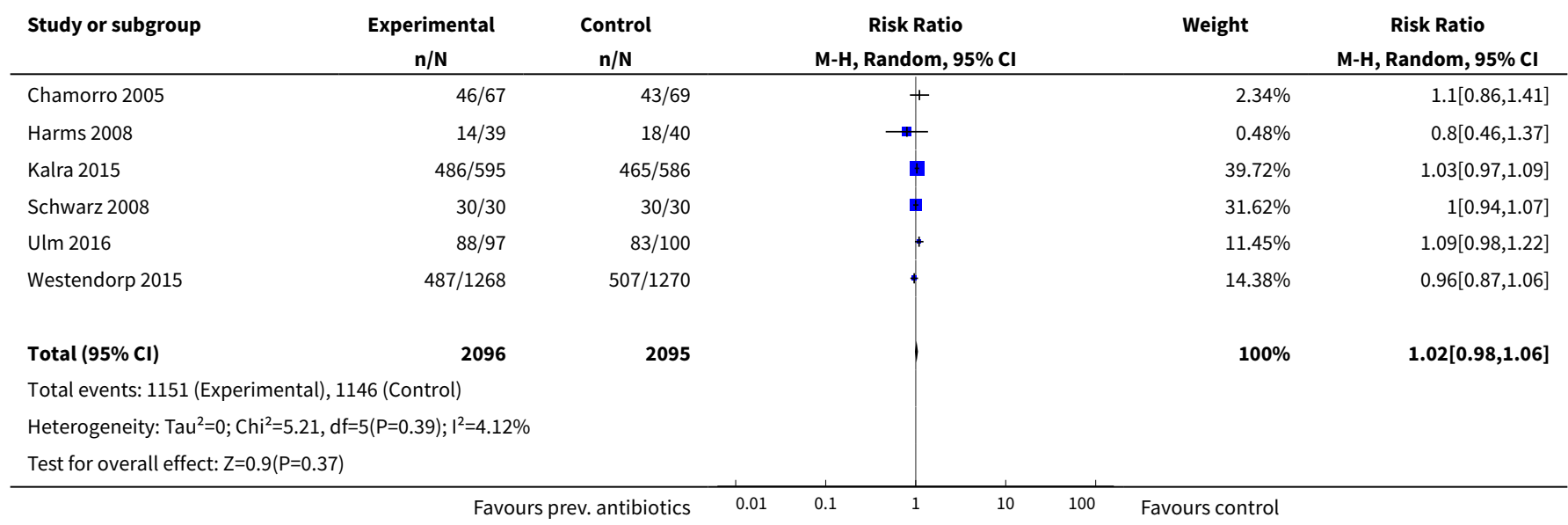

Analysis 3.2. Comparison 3 Forest plot of comparison: sensitivity analyses, Outcome 2 Number of infections: low risk of bias studies.

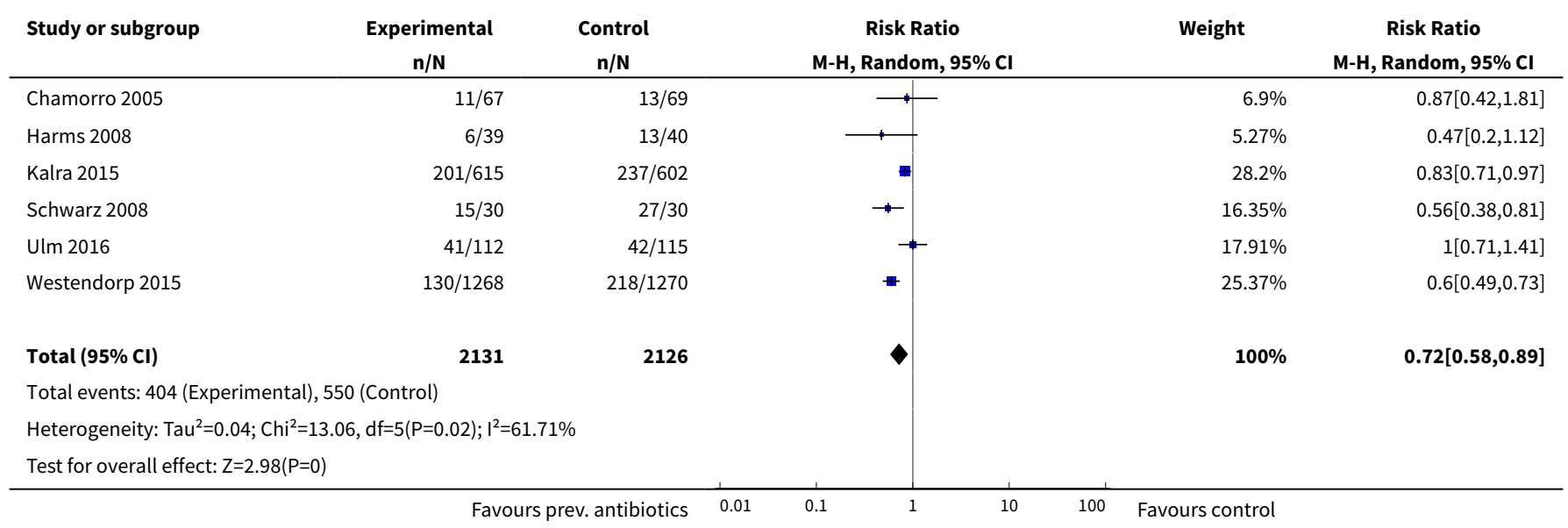


Analysis 3.3. Comparison 3 Forest plot of comparison: sensitivity analyses, Outcome 3 Case fatality: double-blind design.

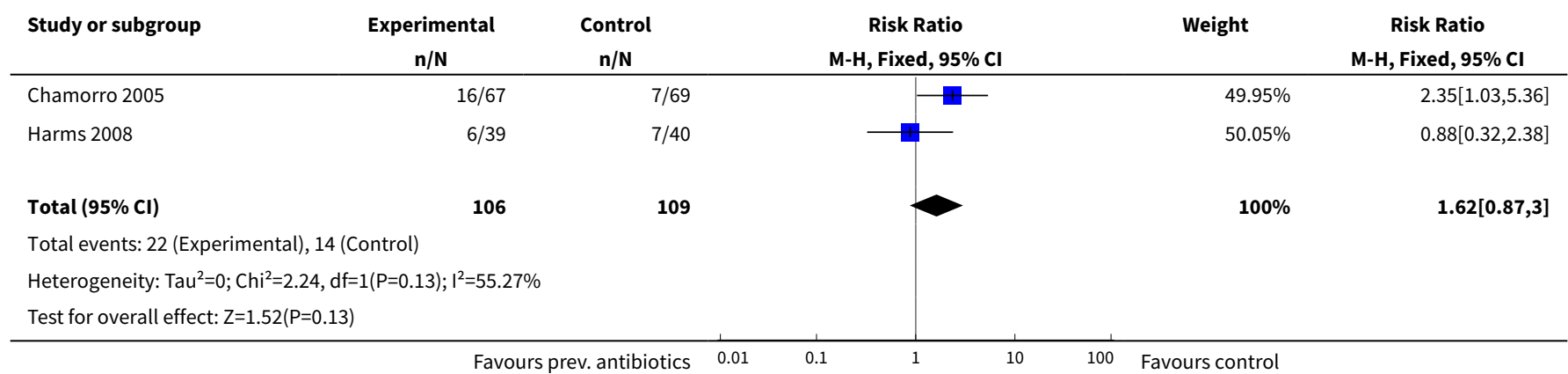

Analysis 3.4. Comparison 3 Forest plot of comparison: sensitivity analyses, Outcome 4 Case fatality: open-label design.

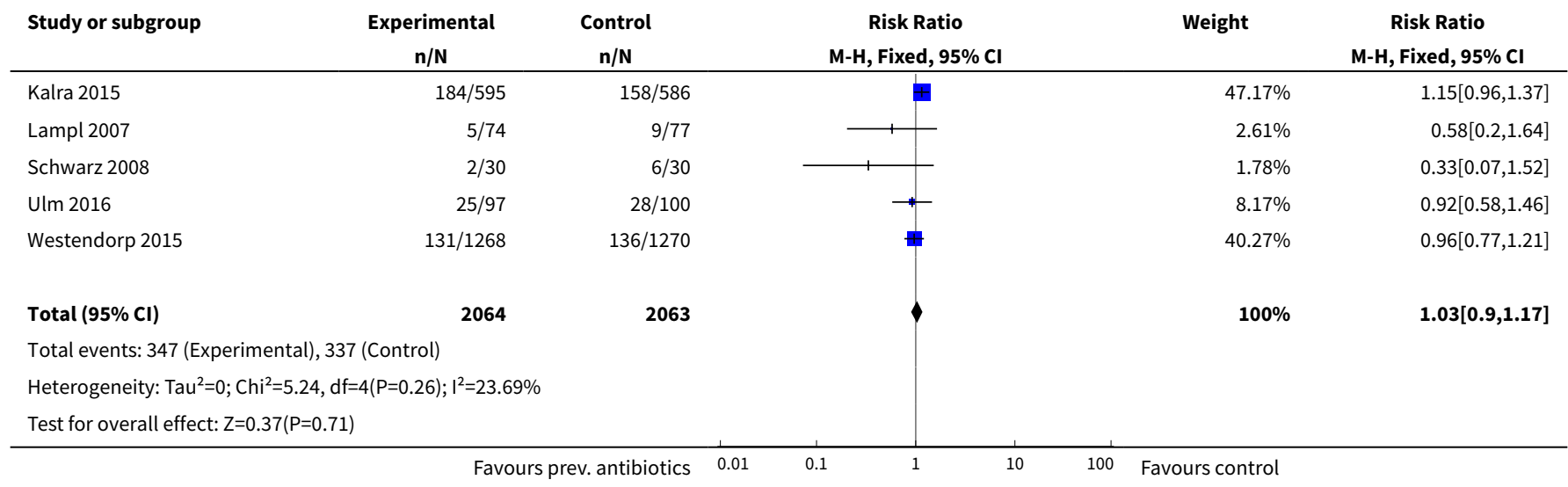

Analysis 3.5. Comparison 3 Forest plot of comparison: sensitivity analyses, Outcome 5 Functional outcome: double-blind design.

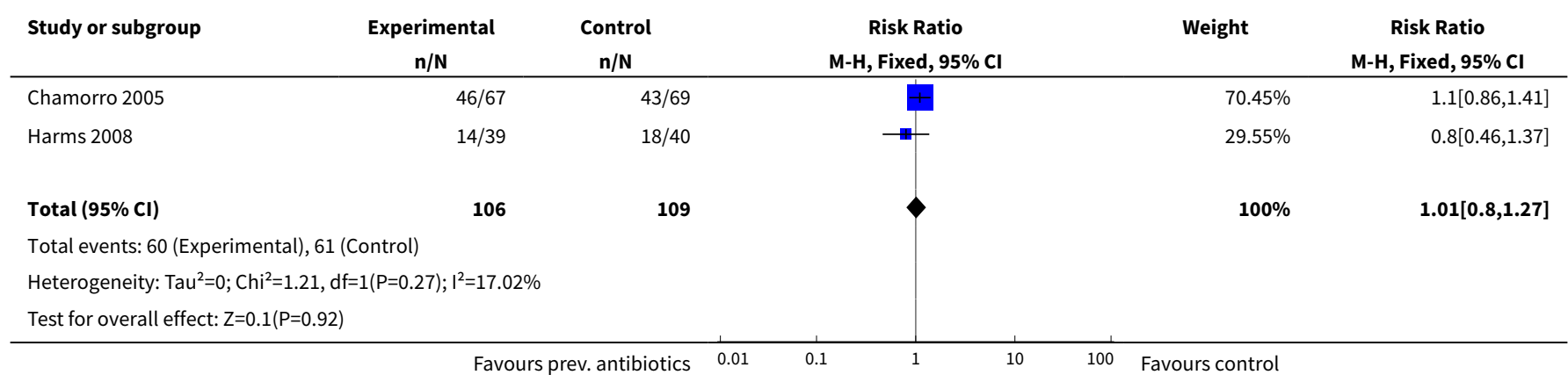




\section{Analysis 3.6. Comparison 3 Forest plot of comparison: sensitivity} analyses, Outcome 6 Functional outcome: open-label design.

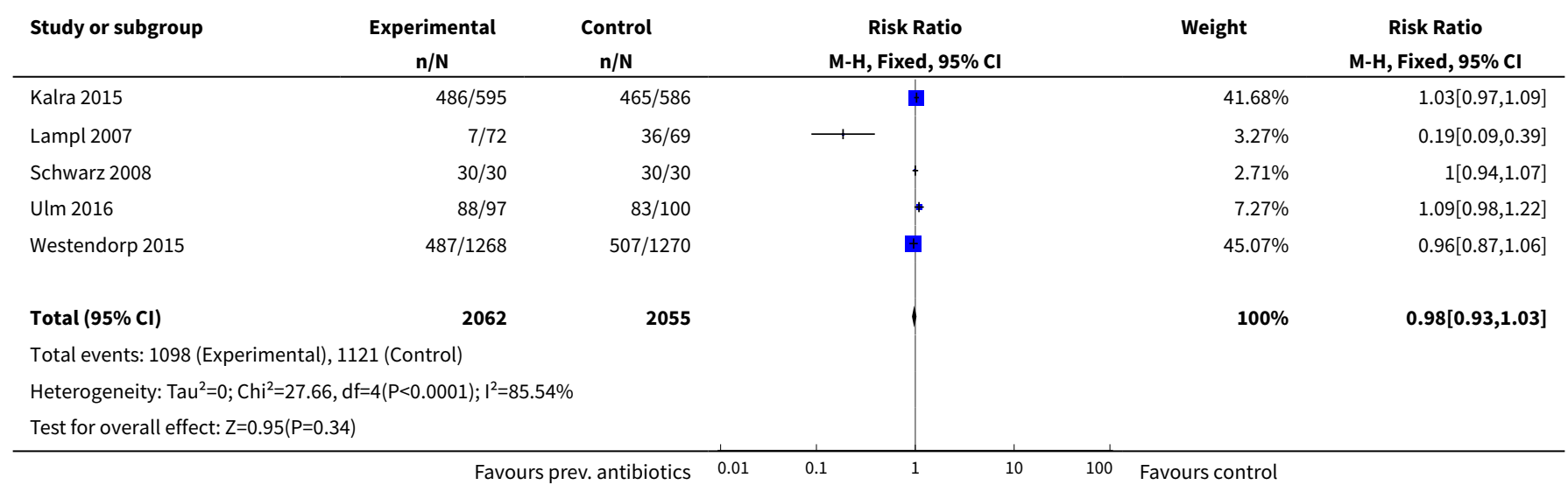

\section{APPENDICES}

\section{Appendix 1. CENTRAL search strategy}

We used the following search strategy for the Cochrane Stroke Group's Trials Register and the Cochrane Central Register of Controlled Trials (CENTRAL).

- Stroke AND antibiotics.

- Haemorrhage AND antibiotics.

- Stroke AND prophylaxis.

- Haemorrhage AND prophylaxis.

- Stroke AND infection.

- Haemorrhage AND infection.

\section{Appendix 2. MEDLINE Ovid search strategy}

We used the following search strategy for MEDLINE Ovid.

- cerebrovascular disorders/ or exp basal ganglia cerebrovascular disease/ or exp brain ischemia/ or exp carotid artery diseases/ or exp cerebrovascular trauma/ or exp intracranial arterial diseases/ or exp intracranial arteriovenous malformations/ or exp "intracranial embolism and thrombosis"/ or exp intracranial hemorrhages/or stroke/ or exp brain infarction/ or vasospasm, intracranial/ or vertebral artery dissection/

- (stroke\$ or poststroke\$ or cva\$ or cerebrovascular\$ or cerebral vascular).tw.

- ((cerebral or cerebellar or brain\$ or vertebrobasilar) adj5 (infarct\$ or isch?emi\$ or thrombo $\$$ or apoplexy or emboli\$)).tw.

- ((cerebral or intracerebral or intracranial or brain or cerebellar or subarachnoid) adj5 (haemorrhage or hemorrhage or haematoma or hematoma or bleeding or aneurysm)).tw.

- 1 or 2 or 3 or 4

- Antibiotic Prophylaxis/

- $\exp$ Anti-Bacterial Agents/

- (antibiotic\$ or anti-bacterial or anti bacterial or antibacterial or bacteriocid\$ or anti-mycobacterial or anti mycobacterial or antimycobacterial or anti-infect\$ or anti infect\$).tw.

- (amoxicillin or amphotericin b or ampicillin or calcimycin or cephalosporin\$ or cephalothin or cephamycin\$ or chloramphenicol or dactinomycin or doxycycline or erythromycin or fluoroquinolone\$ or gentamicin\$ or kanamycin or minocycline or neomycin or oxytetracycline or penicillin or streptomycin or tetracycline or vancomycin).tw.

- 7 or 8 or 9

- exp infection/ or exp bacterial infections/or exp infection control/or exp fever/ or exp inflammation/

- (infection\$ or sepsis or septicaemia or septicemia or pneumonia or bacteremia or bacteraemia or inflammation or fever or blood poisoning).tw. 
- 11 or 12

- (prophyla\$ or prevent $\$$ or premedicat\$ or incidence or occurrence).tw.

- prevention control.fs.

- 15 or 14

- 10 and 13 and 16

- 6 or 17

- 5 and 18

\section{Appendix 3. Embase Ovid search strategy}

We used the following search strategy for Embase Ovid.

- cerebrovascular disease/ or basal ganglion hemorrhage/ or exp brain hematoma/ or exp brain hemorrhage/ or exp brain infarction/ or exp brain ischemia/ or exp carotid artery disease/ or exp cerebral artery disease/ or cerebrovascular accident/ or exp cerebrovascular malformation/ or exp intracranial aneurysm/ or exp occlusive cerebrovascular disease/ or stroke/

- stroke unit/ or stroke patient/

- (stroke\$ or poststroke\$ or cva\$ or cerebrovascular\$ or cerebral vascular).tw.

- ((cerebral or cerebellar or brain\$ or vertebrobasilar) adj5 (infarct\$ or isch?emi\$ or thrombo or apoplexy or emboli\$)).tw.

- ((cerebral or intracerebral or intracranial or brain or cerebellar or subarachnoid) adj5 (haemorrhage or hemorrhage or haematoma or hematoma or bleeding or aneurysm)).tw.

- 1 or 2 or 3 or 4 or 5

- antibiotic prophylaxis/

- exp antibiotic agent/

- (antibiotic\$ or anti-bacterial or anti bacterial or antibacterial or bacteriocid\$ or anti-mycobacterial or anti mycobacterial or antimycobacterial or anti-infect\$ or anti infect\$).tw.

- (amoxicillin or amphotericin b or ampicillin or calcimycin or cephalosporin\$ or cephalothin or cephamycin\$ or chloramphenicol or dactinomycin or doxycycline or erythromycin or fluoroquinolone\$ or gentamicin\$ or kanamycin or minocycline or neomycin or oxytetracycline or penicillin or streptomycin or tetracycline or vancomycin).tw.

- 8 or 9 or 10

- exp infection/ or infection control/ or infection risk/ or fever/ or exp inflammation/

- (infection\$ or sepsis or septicaemia or septicemia or pneumonia or bacteremia or bacteraemia or inflammation or fever or blood poisoning).tw.

- 12 or 13

- (prophyla\$ or prevent $\$$ or premedicat\$ or incidence or occurrence).tw.

- prophylaxis/

- 16 or 15

- 11 and 14 and 17

- infection prevention/ or exp infection/pc

- 11 and 19

- 7 or 18 or 20

- 6 and 21

\section{Appendix 4. Clinical trials and research registers search strategy}

We used the following search strategy for ClinicalTrials.gov (www.clinicaltrials.gov).

- Stroke AND antibiotics.

- Stroke AND infection.

We used the following search strategy for the ISRCTN Registry (www.isrctn.com).

- Stroke AND antibiotics.

- Stroke AND infection.

We used the following search strategy for the Stroke Trials Registry (www.strokecenter.org/trials).

- Antibiotics.

- Infection. 
We used the following search strategy for the WHO Registry Platform (apps.who.int/trialsearch).

- Stroke AND antibiotics.

- Stroke AND infection.

Appendix 5. Definitions used for infection

\begin{tabular}{ll}
\hline Source & Definition \\
\hline Chamorro 2005 & $\begin{array}{l}\text { Temperature }>37.5^{\circ} \mathrm{C} \text { in } 2 \text { determinations; or }>37.8^{\circ} \mathrm{C} \text { in a single determination in participants with } \\
\text { suggestive symptoms; white blood cell count }>11,000 / \mathrm{mL} \text { or }<4000 / \mathrm{mL} \text {; pulmonary infiltrate on } \\
\text { chest } x \text {-rays, or cultures positive for a pathogen. Early infection: within } 7 \text { days, late: } 8 \text { to } 90 \text { days }\end{array}$ \\
\hline De Falco 1998 & $\begin{array}{l}\text { Infectious complications: bronchopulmonary, urinary, or hyperthermia of unspecified origin. No } \\
\text { definitions specified }\end{array}$ \\
\hline Harms 2008 & $\begin{array}{l}\text { Pneumonia: }>1 \text { of the following: abnormal respiratory examination, or pulmonary infiltrates in } \\
\text { chest x-rays; productive cough with purulent sputum; microbiological cultures from lower respi- } \\
\text { ratory tract or blood cultures; leukocytosis and elevation of C-reactive protein (CRP). Urinary tract } \\
\text { infection (UTI): }>1 \text { of the following: fever (temperature }>38.0^{\circ} \mathrm{C} \text { ), urine sample positive for nitrite, } \\
\text { leukocyturia, and significant bacteriuria }\end{array}$ \\
\hline
\end{tabular}

Kalra 2015

The algorithm for pneumonia was derived from criteria for pneumonia from the Centers for Disease Control and Prevention that assess 8 clinical or laboratory findings at 6 time points (baseline, 2, 7, 10 , and 14 days) for patient's temperature $\geq 37 \cdot 5^{\circ} \mathrm{C}$ on 2 consecutive measurements, or 1 measurement $\geq 38.0^{\circ} \mathrm{C}$ and a respiratory rate $\geq 20$ breaths per minute, or cough and breathlessness, or purulent sputum, and a white blood cell count $>11.0 \times 10^{9} / \mathrm{L}$, or chest infiltrates on radiograph, or positive sputum culture or microbiology, or positive blood culture

\begin{tabular}{|c|c|}
\hline Lampl 2007 & Not evaluated \\
\hline \multirow[t]{5}{*}{ Schwarz 2008} & $\begin{array}{l}\text { Pneumonia: new infiltrate on chest } x \text {-ray compatible with the diagnosis of infection plus } \geq 1 \text { of the } \\
\text { following: fever (temperature }>38^{\circ} \mathrm{C} \text { ), leukocytosis }>12,000 / \mu \mathrm{L} \text { or leukopenia }<3000 / \mu \mathrm{L} \text {, purulent } \\
\text { tracheal secretions }\end{array}$ \\
\hline & $\begin{array}{l}\text { Tracheobronchitis: purulent tracheal secretions or sputum plus } \geq 1 \text { of the following: fever (temper- } \\
\text { ature }>38^{\circ} \mathrm{C} \text { ), leukocytosis }>12,000 / \mu \mathrm{L} \text {, or leukopenia }<3000 / \mu \mathrm{L}\end{array}$ \\
\hline & $\begin{array}{l}\text { UTI: > } 25 \text { leukocytes/ } \mu \mathrm{L} \text { in the urine if not explained by other findings. Bacteraemia: bacteria in } \\
\text { blood cultures }\end{array}$ \\
\hline & $\begin{array}{l}\text { Sepsis: clinical evidence of an infection with } \geq 2 \text { of the following: temperatures }>38^{\circ} \mathrm{C} \text { or }<35^{\circ} \mathrm{C} \text {, } \\
\text { tachycardia }>90 / \mathrm{min} \text {, tachypnoea }>20 / \mathrm{min} \text {, leukocytosis }>12,000 / \mu \mathrm{L} \text {, or leukopenia }<3000 / \mu \mathrm{L}\end{array}$ \\
\hline & $\begin{array}{l}\text { Infection of unclear origin or other infections: clinical evidence of an infection of unknown origin or } \\
\text { any other systemic infection }\end{array}$ \\
\hline Ulm 2016 & $\begin{array}{l}\text { Infection in the control group is diagnosed by the clinician. In the intervention group, presence of } \\
\text { an infection is guided by ultrasensitive procalcitonin (PCTus) monitoring. In patients with a PCT } \\
\text { concentration }>0.05 \mathrm{ng} / \mathrm{mL} \text {, a bacterial infection is considered likely, and the use of antibiotics is } \\
\text { recommended. The responsible physician will then decide on appropriate treatment based on the } \\
\text { suspected type of infection according to CDC criteria. }\end{array}$ \\
\hline Westendorp 2015 & $\begin{array}{l}\text { Infections were categorised as diagnosed by the clinician, and as judged by an independent adju- } \\
\text { dication committee (masked to treatment allocation) according to modified Centers for Disease } \\
\text { Control and Prevention criteria. The scoring algorithms for infections used by this committee have } \\
\text { been described previously. }\end{array}$ \\
\hline
\end{tabular}


WHAT'S NEW

\begin{tabular}{lll}
\hline Date & Event & Description \\
\hline 25 June 2017 & New search has been performed & $\begin{array}{l}\text { Update of the complete manuscript, including reevaluation of } \\
\text { methods including search strategy, as well as an update of trial } \\
\text { results. }\end{array}$ \\
\hline
\end{tabular}

25 June $2017 \quad$ New citation required and conclusions
have changed

\begin{abstract}
The conclusions of the review have changed. In the previous version of this review, it was not possible to draw conclusions on the effects of 'any' preventive antibiotic on mortality or stroke outcome owing to a small study population with broad heterogeneity. In addition, study sizes were too small to show the effects of preventive antibiotics on specific types of infection. In current updated version, however, study size has increased significantly, making it possible to conclude that preventive antibiotic therapy does not reduce the risk of dependency and/or death, but does significantly reduce the occurrence of 'overall' infection. The latter can now be specified, showing that this reduction is highly significant for urinary tract infections but has no effect on pneumonia.
\end{abstract}

\section{CONTRIBUTIONS OF AUTHORS}

J-D Vermeij (JDV): performed the search, extracted data, and analysed and interpreted data.

WF Westendorp (WW): performed the search, extracted data, analysed and interpreted data, and drafted the review.

DWJ Dippel (DWJD): conceived and designed the review, assessed methodological quality, and provided final approval of the review for publication.

PJ Nederkoorn (PJN): performed analysis and interpretation of the data and commented on the review for its intellectual content.

$\mathrm{D}$ van de Beek (DVDB): commented on the review for intellectual content and provided final approval of the review for publication.

\section{DECLARATIONS OF INTEREST}

J-D Vermeij (JDV): member of the study group of the Preventive Antibiotics in Stroke Study (ISRCTN66140176). WF Westendorp (WW): member of the study group of the Preventive Antibiotics in Stroke Study (ISRCTN66140176). DWJ Dippel (DWJD): member of the study group of the Preventive Antibiotics in Stroke Study (ISRCTN66140176). PJ Nederkoorn (PJN): principal investigator of the Preventive Antibiotics in Stroke Study (ISRCTN66140176). D van de Beek (DVDB): principal investigator of the Preventive Antibiotics in Stroke Study (ISRCTN66140176).

\section{SOURCES OF SUPPORT}

\section{Internal sources}

- Academic Medical Center, Netherlands.

Department of Neurology

- Erasmus Medical Center, Netherlands.

Department of Neurology

\section{External sources}

- ZonMW, Netherlands.

Grant: Netherlands Organisation for Health Research and Development (ZonMW): 171002302

- Netherlands Heart Foundation, Netherlands.

Grant: Netherlands Heart Foundation (Hartstichting): 2009B095 
- Netherlands Organization for Health Research and Development, Netherlands.

Netherlands Organization for Health Research and Development (ZonMw; NWOVeni grant 2006 [916.76.023], NWO-Vidi grant 2010 [016.116.358])

\section{INDEX TERMS}

\section{Medical Subject Headings (MeSH)}

Anti-Bacterial Agents [ ${ }^{\star}$ therapeutic use]; Antibiotic Prophylaxis [methods]; Bacterial Infections [mortality] [ ${ }^{*}$ prevention \& control]; Brain Ischemia [complications]; Pneumonia [epidemiology]; Randomized Controlled Trials as Topic; Stroke [ ${ }^{*}$ complications] [mortality]; Urinary Tract Infections [epidemiology]

\section{MeSH check words}

Humans 